AROUEOLOGÍA Y SOCIEDAD

№ 26, 2013: $369-384$

ISSN: 0254-8062

RECIBIDO: 27 / MAR. / 2013

ACEPTADO: 25 / ABR. / 2013

\title{
ELEMENTOS PARA UN ANÁLISIS DE LA SALUDY ENFERMEDAD EN LA COMUNIDAD DE TUPE
}

\author{
ANDRÉs RAMÍREZ TREBEJO* \\ UNIVERSIDAD NACIONAL MAYOR DE SAN MARCOS \\ andresrat@gmail.com
}

\section{RESUMEN}

El artículo trata sobre la salud y enfermedad en la comunidad y distrito de Tupe, que se ubica en la provincia de Yauyos, departamento de Lima. Desde una perspectiva etnográfica, se describen los servicios que brinda el Puesto de Salud de Tupe y las prácticas tradicionales de curación. Se encuentra, por un lado, la poca cobertura de salud desde el Estado y, por otro lado, la utilización de plantas medicinales y ritos de curación entre la población como forma de tratamiento de la enfermedad. De esta forma, los conocimientos y prácticas tradicionales médicas con las que cuenta la población, constituyen recursos culturales para afrontar a las enfermedades dentro de la limitada cobertura de salud que el Estado destina para poblaciones rurales como Tupe.

Palabras Clave: Salud, enfermedad, herbolaria, sanación, comunidad campesina.

\begin{abstract}
This article talks about the health and disease in the community and district of Tupe, which it is located in Yauyos's province, department of Lima. From an ethnographic perspective, there are described the services that offers the Healthcare center of Tupe and the traditional practices of treatment. One finds, on the one hand, small coverage of health from the State and, on the other hand, the utilization of medicinal plants and rites of treatment between the population as form of treatment of the disease. In this way, the knowledge and traditional medical practices which the population possesses constitute cultural resources to confront to the diseases inside the limited coverage of health that the State destines for rural populations as Tupe.
\end{abstract}

KeYwords: Health, illness, herbal, healing, peasant community.

\section{ANTECEDENTES}

Abordar el tema de la salud y enfermedad en comunidades campesinas del Perú, impone la necesidad de revisar trabajos que han elaborado médicos, antropólogos y entre otros investigadores. Produciéndose en los últimos años, investigaciones que han abordado el cómo fue y cómo sigue reproduciéndose en la actualidad la llamada medicina tradicional y sus prácticas en contextos culturales particulares.

* Antropólogo, UNMSM. Estudios de Maestría en el Programa de Estudios Andinos de la Pontificia Universidad Católica del Perú. 
Sin ánimos de dar una exhaustiva revisión para el caso peruano, uno de los más valiosos trabajos que se han realizado en nuestro medio, es el que hicieron Hermilio Valdizán y Ángel Maldonado en 1922 con su obra La Medicina popular peruana, en que se buscaba establecer continuidades entre los sistemas médicos de la época prehispánica con aquellos que se producían a comienzos del siglo XX, época en que vivieron los autores. De este tipo de trabajo, de corte etnohistórico, es el que también desarrolla posteriormente Fernando Cabieses en Dioses y enfermedades del antiguo Perú (1974) y en Apuntes de medicina tradicional (1993), y que resaltan los diversos conocimientos que poseían las poblaciones prehispánicas en el uso de plantas, minerales y ritos como forma de curación. Del mismo modo, Dora Montalvo de Maldonado, en su Conocimiento médico del Perú Antiguo (2007), realiza un tratado sobre la anatomía y fisiología del cuerpo humano para poder realizar prácticas curativas. Algo similar ocurre con el padre Jorge A. Lira, quien en su Medicina Andina, farmacopea y ritual (1985), recopila recetas y procedimientos sobre métodos terapéuticos y rituales de la medicina tradicional, describe la farmacopea andina y sus rituales de curación. Por otra parte, un trabajo que busca establecer una ontología de la medicina tradicional relacionándolo con la cultura e identidad andina, es el que realiza Efraín Cáceres en Sicrees, los Apus te curan (1988), sostiene que las prácticas tradicionales de curación obedecen a una cosmología más amplia, la llamada «cosmovisión andina», definida esta como el equilibrio entre hombre-naturaleza.

Desde la oficialidad del Estado también se han producido algunos textos que tratan sobre la medicina tradicional. Por ejemplo, el desaparecido Instituto Nacional de Medicina Tradicional (INMETRA), publicó varios folletos de Delgado Súmar, Salud y enfermedad en el mundo andino (s/f) y los Especialistas en la medicina tradicional (¿1991?), donde se describe la medicina tradicional.

Mucho más reciente, es una importante publicación editada por Ricardo Sánchez Garrafa y Rodolfo Sánchez Garrafa, Medicina Tradicional Andina. Planteamientos y aproximaciones (2009), que contiene varios estudios que plantean perspectivas teóricas para conceptualizar a la medicina tradicional y analizar su articulación con la llamada medicina moderna.

Si bien esta es una revisión somera sobre algunos textos importantes que se han producido sobre el tema en cuestión, y que serán de referentes para el presente artículo, se puede concluir que el tema de la salud y enfermedad se ha visto desde varios frentes. Por un lado, desde la medicina, la antropología, y enfoques etnohistóricos. Por otro lado, aquellos que buscan dar fundamentos epistemológicos y teóricos para interpretar a la medicina tradicional en diversos contextos sociales.

Respecto al presente trabajo, se espera que constituya una contribución a los estudios de la llamada «antropología de la salud», en la medida que se etnografía los sistemas médicos de una localidad con mucha historia y tradición en los estudios de las ciencias sociales, la comunidad de Tupe, en la provincia limeña de Yauyos. El estudio que presento no busca ver continuidades históricas y supervivencias de la medicina prehispánica, sino analizar que en dicha localidad se recurre a conocimientos médicos tradicionales como mecanismos para enfrentar las enfermedades dentro de las limitaciones y la poca cobertura de los sistemas de salud estatal. Si bien el poblador recurre a la medicina moderna y tradicional, es esta última la que llega a constituirse como un referente para buscar mejoría y sanación a las enfermedades y males que se le presenta en su vida cotidiana.

\section{LA COMUNIDAD CAMPESINA DE TUPE}

En 1946, luego de fundarse el Instituto de Etnología de San Marcos, se estableció como necesidad científica el conocimiento sistemático de las poblaciones rurales, especialmente de las comunidades indígenas, llamadas así por aquellos años. En ese afán, el mencionado Instituto, llevó a cabo el «Proyecto Comunidad de Tupe», con el fin de registrar todos los aspectos de la cultura tupina, sus características y las interrelaciones que existían entre ellas. De este modo, desde el año 1948 hasta el año 1953 se desarrolló una importante investigación antropológica en la zona de Yauyos. Se contó con la participación de profesionales y de estudiantes de diversas áreas: José Matos Mar; Rosalía Avalos; Carmen Delgado; Emma Cerrate; Oscar Tovar; Juan Elías Flores; entre otros (Valcárcel 1953). 
De este modo, la Comunidad de Tupe fue definida como el único centro del área cultural del Kauke -llamado así por aquel entonces-, que mostraba supervivencias del mundo prehispánico, tanto en la forma de producción, la organización social, la cosmovisión y principalmente la lengua. Se registró un importante material que fue base para una serie de publicaciones que mostraban las características de esta área o «relicto cultural» del jaqaru en el Perú (Matos Mar 1949, 1951 y 1956; Ávalos 1951; Delgado 1965).

La Comunidad Campesina de Tupe se ubica en la serranía de Lima, en la provincia de Yauyos, a una altitud de 2850 msnm. Pertenece al distrito del mismo nombre creado en el año de 1936. Según el Censo Nacional del año 2007, posee una población de 655 habitantes: 319 hombres y 336 mujeres. Además de la existencia de la Comunidad Campesina de Tupe, también está la Comunidad de Aiza, constituida a fines de la década de 1960.

\section{ACTIVIDAD ECONÓMICA}

La población se dedica a la ganadería y la agricultura. La ganadería está constituida por la cría de ganado vacuno, ovino, caprino, que son propiedades de familias comuneras y de criaderos particulares. Del vacuno, extraen cuero y leche para la elaboración del queso, que son comercializados en Cañete y Lima. Del ganado ovino, que crían preferentemente en los pastales comunales de puna, se aprovecha la lana, el cuero, la carne, las que también son comercializadas. Los camélidos sudamericanos (llamas y alpacas), que se pastan en la puna (4500 msnm) y están bajo el resguardo de la empresa comunal, que depende de la Comunidad de Tupe. De estos camélidos se extrae fibras de diversos tipos y calidades, que son vendidas a Huancayo y Lima. La agricultura, por otra parte, constituye la principal fuente económica y productiva de los pobladores. Se produce, mayoritariamente, para el consumo familiar, y una pequeña parte para su venta. Se cultivan papas, ocas, camote, habas, maíz, de acuerdo a las altitudes de sus tierras de cultivo y, en los últimos años, se están sustituyendo por frutales, que años antes se producía solo en la comunidad de Catahuasi, situada en cabecera de costa. Se sigue trabajando la tierra en base a lazos de parentesco y reciprocidad, tanto para la siembra como para la cosecha, y para la realización de estas actividades se hace uso de tecnologías tradicionales como los andenes y el arado andino, conocido como la Txajlla.

\section{CULTURA Y LENGUA}

La Comunidad de Tupe posee muchos conocimientos ancestrales con respecto a la producción agrícola, la reciprocidad andina, la cosmovisión religiosa, asimismo mantiene su lengua: el jaqaru. Según Hardman (1983) esta lengua pertenece a la familia lingüística Jaqi, emparentada con el aimara y el kau$k i$, hablada esta última solo por una persona en el anexo de Cachuy, distrito de Catahuasi en Yauyos ${ }^{1}$. Actualmente, en Tupe donde viven el mayor número de hablantes de jaqaru, si bien cada día son menos, pero que utilizan el castellano en el habla cotidiana, dejando a la lengua vernácula solo para el espacio privado, los adultos mayores y en interacciones particulares ${ }^{2}$.

\section{SITUACIÓN ACTUAL}

Tupe, pese a su tradicionalidad en sus formas de producción y manifestaciones culturales, se encuentra en una situación de pobreza y exclusión. Se ubica, por ejemplo, en el quintil dos del Mapa de Pobreza ${ }^{3}$, sin servicios básicos como el desagüe, carretera y educación bilingüe.

1 Sobre la cantidad de hablantes de kauke en Cachuy, fue recogido de un congreso sobre normalización del alfabeto Jaqaru, Tupe. 2010.

2 Según el Mapa Etnolinguístico (2009) el jaqaru tiene un aproximado de 1200 hablantes.

3 Mapa de Pobreza Distrital de FONCODES 2006, con indicadores actualizados con el Censo de 2007. Se detalla que Tupe se encuentra en el quintil 2, en donde posee el $100 \%$ de población sin agua y sin desagüe; el 45\% sin electricidad, el 23\% mujeres analfabetas y con una tasa de desnutrición de niños de 6 a 9 años en un $49 \%$. 
Sumado a ello, desde hace algunos años, se vivió en Tupe una situación conflictiva entre la comunidad campesina y el gobierno distrital, debido a la permanencia en el cargo del ex alcalde distrital, acusado de corrupción y poca gestión municipal. Tras lo cual terminó en una revocatoria y que significó un proceso de lucha por reconocimiento político y social frente al Estado, debido a las prácticas no democráticas que suelen reproducirse en ámbitos rurales (Ramírez 2010).

En síntesis, en Tupe se hallan formas tradicionales de organización, producción e identidad, pero dentro de relaciones sociales, económicas y políticas, que van desde lo regional, nacional e internacional; tanto por la migración constante de sus pobladores, el consumo tecnológico, y sobre todo, por acciones colectivas para establecer derechos ciudadanos, como la lucha por tener Educación Intercultural Bilingüe y prácticas democráticas al interior del distrito (Ramírez 2012; 2010). Aunque si bien se sigue representando a Tupe como un lugar «detenido en el tiempo» (Vetter y MacKay 2008), y como pueblo tradicional con matrices culturales prehispánicas (Matos 1984; Bautista 2010a), ya no puede definirse como tal pues está en constante relación con ámbitos nacionales, lo que permite, por ejemplo, la lucha por el reconocimiento oficial del alfabeto jaqaru y, por otro, la aún poca cobertura de servicios básicos, como la salud.

\section{SistemA MÉDICO EN TUPE}

Antes de empezar a describir los servicios de salud que se encuentran en Tupe, debemos entender que dichos servicios (atenciones, curaciones, medicinas, etc.) obedecen a la práctica de sistemas médicos específicos y que se presentan en todas las sociedades humanas. Por ello, un sistema médico se podría definir como un:
«[...] cuerpo de doctrina que rige en los problemas de salud y de enfermedad en una cultura determinada [...]. En este sentido [...] debe tener conceptos propios de lo que es la salud y la enfermedad; de lo que es la vida y la muerte; de cuáles son las diversas causas de la enferme- dad, y cómo pueden contrarrestarse para recuperar la salud; de cuál debe ser, en esa comu- nidad, la jerarquía social del encargado de curar y cuidar a los enfermos; de cuál debe ser la participación de la comunidad en la salud de sus miembros[...]» (Cabieses 1993: 1).

Por tanto, en Tupe se encuentran dos sistemas médicos relacionados y no excluyentes: la medicina moderna y la tradicional. Ambas poseen sus propias formas doctrinales por las cuales se entiende la enfermedad y curación. Por el momento, conviene detenernos en apreciar algunas características de la medicina moderna, la cual está definida e impartida desde la institucionalidad estatal; y luego, la medicina tradicional, la cual tiene mucha presencia en toda la localidad. Para posteriormente, analizar el funcionamiento e interrelaciones que se producen entre las lógicas de ambos sistemas médicos.

\section{MEDICINA MODERNA}

La medicina moderna puede entenderse desde concepciones ontológicas, las cuales están basadas en el pensamiento científico occidental para construir marcos interpretativos sobre la salud, la enfermedad y la curación. Se caracteriza por estar dentro de un modelo biomédico, que tiene como rasgo principal el ser organicista, de orden curativo y especializado. En otras palabras, es organicista en la medida que la enfermedad es entendida a partir de los órganos y el sistema corporal; es curativa, porque el objetivo es el diagnostico, curación y control de las enfermedades; y especializado, en cuanto existen especialistas para cada órgano y enfermedad (Zuluaga 2009: 255-256).

Esta forma de concebir a la medicina moderna como un sistema biomédico genera que las políticas de salud que realiza el Estado estén orientadas a conceptuar a la enfermedad únicamente como disfunciones de los órganos y los sistemas corporales. Haciendo que el objetivo sea la prevención y curación a cargo de un especialista para cada tipo de enfermedad. Se obvia así, a aquellas otras formas de concebir las enfermedades, como las que se presentan en contextos culturales particulares. 
En Tupe, la medicina moderna está representada por el servicio médico que brinda el Puesto de Salud (Fig. 1). Es la única institución médica estatal que existe en el distrito. Cuenta con poco personal médico y técnico para atender a toda la población. Por ejemplo, en el año 2008, solo se tuvo a una técnica en enfermería. Actualmente, hay dos personas, una técnica en enfermería y un enfermero, para atender aproximadamente a 655 personas que están distribuidas en los anexos de Aiza y Colca, y en el pueblo de Tupe. El personal suele residir en las instalaciones del Puesto de Salud, pues se tiene ambientes como la cocina, dormitorios y un baño. En ocasiones se cuenta con enfermeras que provienen del SERUM ${ }^{4}$, pero luego de terminar su labor de un año de servicio se retiran de la localidad. Esto ocasiona un serio problema para el servicio de salud, pues no se cuenta con la continuidad de un personal médico adecuado, lo que genera dificultades para las atenciones médicas, generado entre la población la percepción que el agente de salud se encuentra distante de ellos.

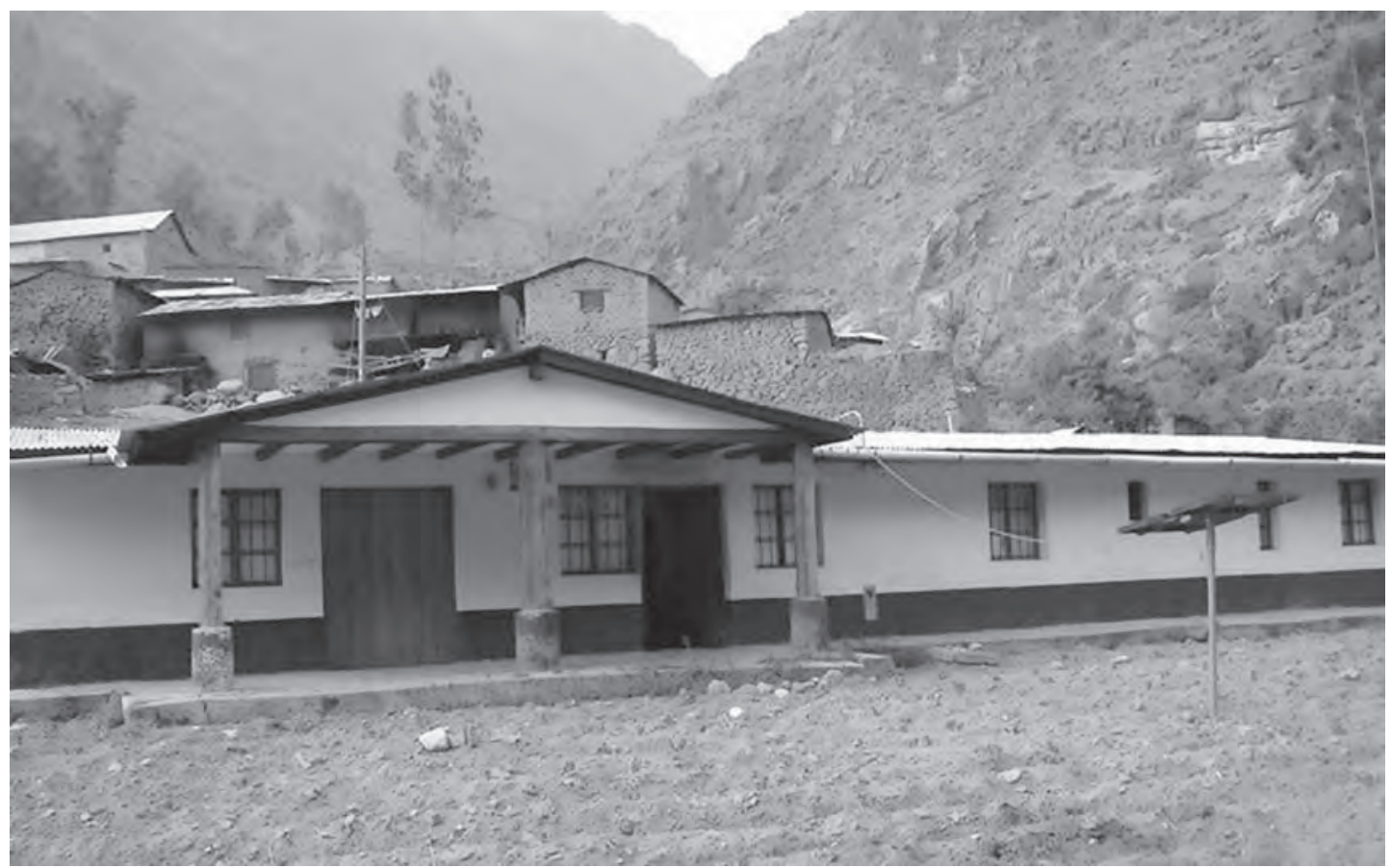

Figura 1. Puesto de salud de Tupe.

El Puesto de Salud de Tupe cuenta con escasos equipos: dos balanzas, un refrigerador (para las vacunas), una camilla y un radio de frecuencia, con el cual están en comunicación con el hospital del pueblo de Catahuasi, el más cercano a Tupe. Esta radio sirve para pedir ayuda a Catahuasi, en caso se tuviese alguna emergencia que implique el traslado de inmediato del enfermo. También con la radio se coordina las visitas de los inspectores y brigadas de salud que se organiza dos veces al mes en todo el distrito. Por otro lado, el ritmo de trabajo del escaso personal es de 25 días al mes, de los cuales tienen 5 días libres; sin embargo, de los 25 días de actividad se utilizan algunos para ir a Catahuasi o Cañete a presentar informes sobre las atenciones y las medicinas que el Puesto de Salud ha expedido. Todo ello genera que las atenciones no sean de forma regular, lo que causa gran malestar entre la población. Por lo cual es muy común escuchar quejas sobre la atención, como cuando dice un pobla-

4 El SERUM, siglas de Servicio Rural y Urbano Marginal de Salud, el cual está diseñado por el Ministerio de Salud para orientar actividades preventivos-promocionales de centros de salud en zonas urbanos marginales y rurales. [En línea]. <http://www.minsa.gob.pe/servicios/serums/2009/default.asp>. 
dor que: «El servicio de la posta es pésimo, no hay atención, en la posta no hay atención constante, atiende 3,4 días y se va»5.

El Puesto de Salud brinda servicios enfocados hacia la medicina preventiva y curativa. Sobre la primera, se enfoca en la administración de vacunas para los recién nacidos, las evaluaciones preventivas a niños y adolescentes frente a la tuberculosis, las IRAS (Infecciones Respiratorias Agudas), malestares estomacales, descartar casos de bartonelosis ${ }^{6}$, zoonosis $^{7}$, y casos de uta ${ }^{8}$. Las evaluaciones que se realizan ayudan a tener registros de las enfermedades más recurrentes que aquejan a la población. Por ejemplo, en el primer trimestre del año 2008 se encontró un caso de uta, 41 casos de infecciones respiratorias y bronquitis entre niños cuyas edades oscilaban entre menos de 1 año hasta los 9 años, y dentro de ellos, los más afectados fueron los menores de 1 año hasta los 4 años, con una ocurrencia de 31 casos, y los de 5 a 9 años, con 10 casos registrados. En casos de embarazos, los técnicos suelen acudir a los hogares para los controles correspondientes. Es poco frecuente que las mujeres en gestación acudan al Puesto de Salud y es el personal técnico quien acude hacia ella pese a la dificultad en el desplazamiento entre un anexo a otro dentro del distrito. Respecto a lo curativo, el Puesto de Salud expide inyecciones, analgésicos, los que por lo general son empleados para atender a dolores de cabeza, de muelas, gripes, entre otros. Uno de los problemas que más se ha encontrado a partir de las conversaciones con la población es respecto a la salud bucal, tanto en niños como en adultos. No existe un odontólogo en el distrito quien pueda curar o extraer dientes y muelas, ocasionando que la población deba trasladarse hacia Cañete, Yauyos o Lima para tratarse estos malestares, si es que pueden costearse el viaje y demás gastos médicos.

Por otra parte, también se brinda el Seguro Integral de Salud (SIS), al cual se accede previa inscripción de la población con el pago de un nuevo sol, tanto para escolares como para personas mayores. Según el Censo del año 2007, Tupe cuenta con 349 asegurados, que están distribuidos de la siguiente manera: 327 con el Sistema Integral de Salud; 18 con el seguro de EsSalud; 4 con otro tipo de seguro; y una alarmante cifra de 306 personas que no cuentan con ningún tipo de seguro\%. Estas cifras oficiales se confirman con el testimonio de la enfermera, quien refiere que:

«En Tupe el 50\% están asegurados, la gente se queja porque antes era el Seguro menores de 17 años y gestantes, ahora es 'seguro para todos'. Pero el Seguro no cubre toda la medicina, 'señorita porqué Ud. me cobra, es un engaño'. Las inyecciones no salen por el SIS, el carbonato de calcio también, ya no pasa por el SIS» ${ }^{10}$.

Esto último que refiere la enfermera es otro de los problemas que se tiene entre la población y el Puesto de Salud: el malestar por los medicamentos. Si bien algunos de estos son entregados gratuitamente por el SIS, la población reconoce que dichas medicinas no son efectivas a diferencia de aquellas que son vendidas y que tienen mayor costo. Estas no llegan a ser subsidiadas por el SIS, ocasionando que la población perciba como un maltrato desde el Puesto de Salud y su personal, que se venda los medicamentos que sí son efectivos para las enfermedades que se presentan.

5 Entrevista a poblador. Tupe, 2008.

6 Enfermedad infecciosa producida por la bacteria del género de la Bartonella. La llamada Enfermedad de Carrión, es producida por una bacteria de este género.

7 Enfermedad que puede trasmitirse de animales a seres humanos, tales como el carbunco, fiebre amarilla, peste bubónica, sarna, entre otros.

8 Su nombre científico es Leishmaniasis. Es una afección que genera ulceraciones a la piel producto de la picadura de un mosquito transmisor.

9 Fuente: INEI - Censos Nacionales 2007: XI de Población y VI de Vivienda.

10 Entrevista a Técnica en enfermería. Tupe. 2008. 
Una de las estrategias que ha diseñado el personal del Puesto de Salud es la formación de promotoras como mecanismo para complementar los servicios que brindan. Estas promotoras están conformadas por mujeres del lugar, quienes se inscriben voluntariamente al programa, siendo capacitadas en primeros auxilios, conocimientos sobre medicamentos e inyectables. Por lo general se cuenta con una promotora de salud para cada poblado, tanto en el anexo de Aiza, Colca y en el pueblo de Tupe. La enfermera refiere al respecto: «El promotor de salud se le da una capacitación, le brinda medicamentos, capacitación, cuando el personal de salud no atiende, ellos atienden» ${ }^{11}$.

Además de las promotoras, el hospital de Catahuasi suele enviar enfermeros, técnicos y médicos a Tupe, como parte de las brigadas de salud que se organizan en coordinación con el Puesto de Salud. Pese a todos estos esfuerzos para expandir la asistencia médica en Tupe se encuentran deficiencias en su ejecución, pues como refiere la enfermera no se llega a cubrir a todos los poblados del distrito:

«Hago mis brigadas, programo dos días de brigadas, 2 días de atención de salud, para esto apoya la Macro Región de Catahuasi. Todo un equipo, dos días, mañana en Aiza, pasado en Tupe, odontología, vacunación, medicina general, psicología. Los doctores no van a Colca, a Colca soy la única que voy» ${ }^{12}$.

En síntesis, se encuentra que el Puesto de Salud de Tupe cuenta con escaso personal, limitado equipo médico y pocas medicinas, lo que hace difícil atender a todo el distrito. Y aunque se tiene el apoyo de las promotoras y las brigadas de salud, estas no se llegan a constituir un mecanismo efectivo para asegurar las atenciones de salud a toda la población y en todos los anexos del distrito.

\section{MEDICINA TRADICIONAL}

Ahora toca dar algunos alcances para entender a la medicina tradicional y ver cómo esta funciona entre los pobladores del distrito de Tupe. Se encuentra una primera definición desde un organismo internacional, la Organización Mundial de la Salud (OMS) que en 1978 la definió como:

«[...] la suma de todo los conocimientos teóricos y prácticos, explicables o no, utilizados para diagnóstico, prevención y supresión de trastornos físicos, mentales o sociales, basados exclusivamente en la experiencia y la observación, y transmitidos verbalmente o por escrito de una generación a otra» (OMS 1978; citado en Zuluaga 2009: 258).

Con esta definición se entiende a la medicina tradicional como un conjunto de conocimientos médicos que se basan en la experiencia y observación, sin embargo, no se considera que dichos conocimientos estén situados dentro de contextos culturales, sociales e históricos específicos.

Es decir, apreciar que los sistemas médicos no occidentales expresan una cosmovisión y formas culturales particulares. Sobre esto Zuluaga (2009) señala que:

«Para que una medicina pueda ser considerada como tradicional, además de sus elementos teóricos-prácticos, debe cumplir con el requisito de tener un arraigo histórico, un arraigo cultural y un arraigo social, en el entramado de la tradición de un pueblo. La medicina tradicional se define en concordancia con la tradición del pueblo que la utilice. Por lo tanto, puede hablarse de diferentes medicinas tradicionales, según hagamos referencia a los indígenas de la Amazonía, a las poblaciones aborígenes del centro de África y a los pueblos del Extremo Oriente, por ejemplo» (p. 263).

11 Ibíd.

12 Ibíd. 
Atendiendo a esta definición, entendemos que la medicina tradicional constituye un entramado de conocimientos que están mediados por la tradición y la historia, las cuales permiten dar significados a los estados de salud, enfermedad y las formas de curación. Siguiendo esta definición, en Tupe se encuentra que la medicina tradicional tiene presencia entre los pobladores, pues existen conocimientos sobre el uso de plantas, hierbas, técnicas y ritos de curación, las cuales son empleadas para el tratamiento de la enfermedad con el fin de recobrar la salud del individuo.

Para el poblador de Tupe, el conocimiento de plantas y hierbas medicinales está ligado a su vida cotidiana. La mayoría de las familias suelen recurrir a la herbolaria local ante los males estomacales, gripales, respiratorios, musculares y torceduras. Las plantas están presentes en toda la extensión del distrito, desde la parte baja o zona quechua (anexos de Aiza y Colca) hasta las zonas más altas o la puna, a más de $45000 \mathrm{msnm}$. Son recogidas mientras los pobladores transitan de un lado a otro, como cuando van a pastar a sus ganados, cultivar en sus chacras, y cuando se trasladan a la puna, en donde se suele encontrar mayor variedad de plantas para usos medicinales. Todas ellas son almacenadas en sus cocinas, y otras, son cultivadas en huertos cercanos a sus casas y se las recoge a la hora de necesitarlas. En algunas ocasiones, mujeres tupinas las comercializan en el anexo de Canchán, en el distrito de Catahuasi o a los feligreses que participan de las celebraciones del Señor de Cachuy en mayo (Fig. 2).

Si bien es de conocimiento común entre la población que existe gran cantidad de plantas y hierbas con propiedades curativas, no se tiene un registro exacto respecto a sus nombres locales, científicos y sus respectivas propiedades. Solo se tiene una lista preliminar que hizo la Dra. Emma Cerrate y el Dr. Óscar Tovar, en la década del 50 como parte de las investigaciones del Instituto de Etnología de San Marcos. Dicha lista la reproducimos a continuación, el cual trae anotaciones de José Matos Mar sobre usos de las plantas (Tabla 1).

Actualmente, las plantas que figuran en la lista de Cerrate y Tovar (1954) son utilizadas por la población para las curaciones respectivas. Estas no están mediadas por personas o especialistas que se dediquen exclusivamente a la curación mediante la herbolaria. Más bien, en Tupe hay la existencia de un conocimiento general compartido entre la población sobre las propiedades y la curación mediante plantas medicinales. Quizá la única forma de especialización es en cuanto al género. Se tiene mayor referencia que quienes suelen realizar las curaciones son las mujeres. En algunas ocasiones, los que realizan las curaciones son los varones que integran la familia o algún amigo cercano. Estas variabilidades en cuanto a la persona que se encarga de curar, y que puede ser cualquier persona sin alguna especificidad, se debe a que el conocimiento sobre las plantas y hierbas medicinales es un saber compartido por las personas de la localidad. Por tanto, no se necesita mayor grado de especialización para administrar infusiones, emplastos, frotaciones, las cuales son practicadas comúnmente por las familias.

Figura 2. Mujer tupina vendiendo plantas medicinales en Canchán (Catahuasi) dentro de las celebraciones del Señor de Cachuy en mayo.

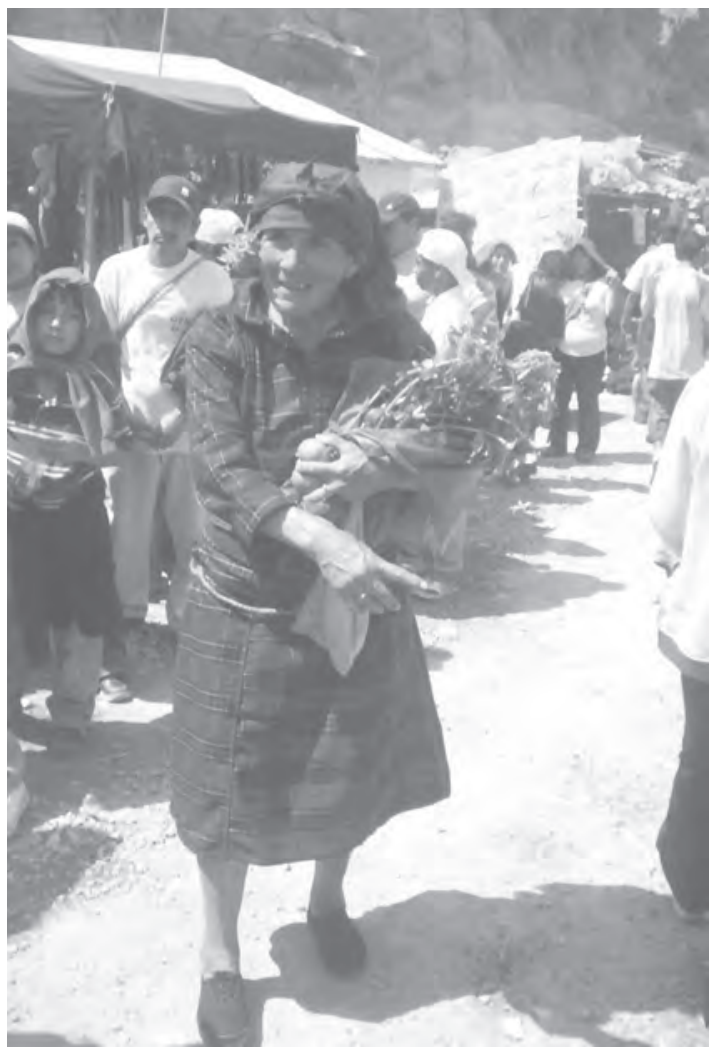


Tabla 1: Lista de plantas medicinales de Tupe.

\begin{tabular}{|c|c|c|}
\hline \multicolumn{3}{|r|}{ PLANTAS DE VEGETACION ESPONTÁNEA EN TUPE } \\
\hline $\begin{array}{l}\text { Nombre } \\
\text { popular }\end{array}$ & $\begin{array}{l}\text { Nombre } \\
\text { botánico }\end{array}$ & Usos \\
\hline Amor seco & Bidens pilosa & $\begin{array}{l}\text { Medicinal. «Para las irritaciones, se toma como té, se usa en lugar de él. Es } \\
\text { refrescante para la vejiga» (J. Matos). }\end{array}$ \\
\hline Berro & $\begin{array}{l}\text { Nasturtium } \\
\text { officinale }\end{array}$ & $\begin{array}{l}\text { Medicinal. Alimenticia. «Es depurativo, corrige la sangre, fresco». (J. Matos). } \\
\text { Crece en lugares pantanosos y bordes de las acequias. }\end{array}$ \\
\hline Camackia & $\begin{array}{l}\text { Chenopodium } \\
\text { ambrosioides }\end{array}$ & $\begin{array}{l}\text { Medicinal y Condimenticia. Se usa para combatir la diarrea de los niños y tam- } \\
\text { bién para condimentar algunas sopas. }\end{array}$ \\
\hline Congona & Peperomia & $\begin{array}{l}\text { Medicinal. «Es bueno para curar el mal de la vista producido por el aire, se } \\
\text { exprime una hojita al ojo. Crece en lugares rocosos» (J. Matos). }\end{array}$ \\
\hline Chillca & $\begin{array}{l}\text { Baccharis lan- } \\
\text { ceolata }\end{array}$ & $\begin{array}{l}\text { Medicinal. Arbusto de hojas resinosas; para curar luxaciones, se tuesta y se apli- } \\
\text { ca a las partes afectadas. Se usa también como leña. }\end{array}$ \\
\hline Escorzonera & $\begin{array}{l}\text { Perezia multi- } \\
\text { flora }\end{array}$ & $\begin{array}{l}\text { Medicinal. Hierba de hojas punzantes, crece solamente en la Puna. Se utiliza } \\
\text { para curar la tos, en infusión. }\end{array}$ \\
\hline Huallhua & $\begin{array}{l}\text { Psoralea pubes- } \\
\text { cens }\end{array}$ & $\begin{array}{l}\text { Medicinal. Arbusto de flores violáceas. Se toma como té para curar dolores de } \\
\text { estómago. }\end{array}$ \\
\hline Huamanripa & Culcitium sp. & $\begin{array}{l}\text { Medicinal y Ornamental crece en la Puna alta, muy estimada para curar la gri- } \\
\text { pe. Dicen «cuando se seca y se tuesta es caliente y cuando está recién cogida es } \\
\text { fresco». Las flores sirven de adorno especialmente a las mujeres. Es una de las } \\
\text { plantas más apreciadas de la Puna. }\end{array}$ \\
\hline $\begin{array}{l}\text { Lengua de } \\
\text { vaca }\end{array}$ & Rumex sp. & $\begin{array}{l}\text { Medicinal. Se hace hervir la planta y con el agua se lavan las heridas, a la vez } \\
\text { que se aplican las hojitas en las heridas. }\end{array}$ \\
\hline $\begin{array}{l}\text { Lenguay- } \\
\text { perro }\end{array}$ & Gnaphalium sp. & $\begin{array}{l}\text { Medicinal. Antiséptico, las hojas por el envés se aplican como gaza para cubrir } \\
\text { las heridas o llagas. }\end{array}$ \\
\hline Llantén & Plantago major & $\begin{array}{l}\text { Medicinal. «Es desinflamante, para curar las heridas; depurativo como el } \\
\text { Berro» (J. Matos). Crece en lugares húmedos, abunda en Cuchapaya-Pampa. }\end{array}$ \\
\hline Maramñay & $\begin{array}{l}\text { Eupatorium } \\
\text { azangaroense }\end{array}$ & $\begin{array}{l}\text { Medicinal. Antiséptico, las hojas se hacen hervir y se ponen emplastos sobre } \\
\text { las heridas. }\end{array}$ \\
\hline Mática & $\begin{array}{l}\text { Jungia panicu- } \\
\text { lata }\end{array}$ & $\begin{array}{l}\text { Medicinal. Antiséptico; después de hacer hervir las hojas, con el agua se lavan } \\
\text { las heridas. También se usa para curar las 'mataduras' de burros, o sea llagas } \\
\text { que se forman en el lomo de estos animales con el exceso de trabajo. }\end{array}$ \\
\hline $\begin{array}{l}\text { Mula- } \\
\text { huanushu }\end{array}$ & Urtica flabellata & $\begin{array}{l}\text { Medicinal. Quita los dolores reumáticos, para lo cual se friccionan con los ta- } \\
\text { llos y hojas que tienen unos pelos urticantes que al penetrar en la epidermis } \\
\text { produce irritaciones. Crece en la Puna. }\end{array}$ \\
\hline Papanshu & Solanum nigrum & $\begin{array}{l}\text { Medicinal. «Es purgante, bueno para curar la enfermedad del tocazón del ga- } \\
\text { nado vacuno. Se mezcla en una lata tuna blanca, jabón, aceite, suero y papans- } \\
\text { hu y se hace tomar al ganado como purgante. 'Tocazón' dicen, cuando se seca } \\
\text { el librillo por falta de agua y cuando las vacas botan sangre y el excremento es } \\
\text { seco. También se aplica al ano para las escaldaduras, etc.» (J. Matos). }\end{array}$ \\
\hline Sabela & Aloe vera & $\begin{array}{l}\text { Medicinal. «Es purgante, las partes blancas se secan al sol y se muelen; una } \\
\text { cucharadita de esto se pone en agua tibia. También cura la tos y la neumonía. } \\
\text { Es madurativo de chupos. Acostumbran colgar en las puertas de las casas para } \\
\text { que no entre gente mala o el hechizo» (J. Matos). }\end{array}$ \\
\hline
\end{tabular}




\begin{tabular}{|l|l|l|}
\hline $\begin{array}{l}\text { Nombre } \\
\text { popular }\end{array}$ & $\begin{array}{l}\text { Nombre } \\
\text { botánico }\end{array}$ & Usos \\
\hline Shumaña & $\begin{array}{l}\text { Minthostachys } \\
\text { mollis }\end{array}$ & $\begin{array}{l}\text { Medicinal y condimenticia. «Para curar la tos, baja la flema, se mastica la hojita } \\
\text { y chupa el jugo» (J. Matos). Además se usa para condimentar sopa de papas. }\end{array}$ \\
\hline Ticlla & Senecio pflanzii & $\begin{array}{l}\text { Planta aromática muy estimada, se toma como té. Crece en la Puna, debajo de } \\
\text { las rocas. }\end{array}$ \\
\hline Trarka & Urtica nigricans & $\begin{array}{l}\text { Medicinal. Hierba utilizada para combatir el reumatismo, se fricciona con el } \\
\text { tallo y hojas, las que tienen pelos urticantes. }\end{array}$ \\
\hline Verbena & Verbena litoralis & $\begin{array}{l}\text { Medicinal: «Hierba de flores azul violetas, crece especialmente en los alfalfa- } \\
\text { res. Purgante y abortivo. Se toma bien verde para curar la terciana. Para curar } \\
\text { las heridas y golpes, la planta se muele con sal y se aplican a la parte afectadas» } \\
\text { J. Matos). }\end{array}$ \\
\hline Wantrarka & $\begin{array}{l}\text { Loasa grandi- } \\
\text { flora }\end{array}$ & $\begin{array}{l}\text { Medicinal. «Planta de hojas grandes y anchas, flores rojas con nectarios bien de- } \\
\text { sarrollados que los muchachos chupan la miel como los picaflores. Bueno para } \\
\text { curar reumatismos, para lo cual se friccionan con las hojas de tallos» (J. Matos). }\end{array}$ \\
\hline $\begin{array}{l}\text { Yahuar- } \\
\text { shoko }\end{array}$ & Oenothera rosea & $\begin{array}{l}\text { Medicinal. «Hierba de flores rosadas. Su nombre quiere decir 'chupa-sangre'. } \\
\text { Bueno para curar las heridas, quita la mala carne» (J. Matos). }\end{array}$ \\
\hline Yerba buena & Mentha sp. & $\begin{array}{l}\text { Medicinal. «Purgante, sudorífero, espasmódico. Es bueno para los abortos. Se } \\
\text { usa también como condimento» (J. Matos). }\end{array}$ \\
\hline
\end{tabular}

Fuente: Cerrate y Tovar (1954)

\section{SALUd Y ENFERMEDAd EN TUPE}

Todas las sociedad humanas, llámese tradicionales o modernas, siempre han tenido marcos de interpretaciones sobre la salud y enfermedad. Se puede tener, por ejemplo, la certeza de que la enfermedad es causada por agentes patógenos externos al individuo y/o por una disfunción en el cuerpo humano, y hasta por explicaciones sobrenaturales. Todas estas formas de entender al estado de salud y enfermedad, revelan los sentidos culturales que los grupos humanos han tejido en su desarrollo.

Según Delgado (s/f), los conceptos de enfermedad y salud están vinculados intrínsecamente pues manifiestan el estado de equilibrio y desequilibrio en tres niveles: individual, grupal y el medio físico. Es decir, la salud está definida a partir del equilibrio que tiene el individuo con el grupo y su medio físico; y, por el contrario, cuando se transgrede dicho equilibrio se produce la enfermedad. Como sostiene el autor: «La Salud en el mundo andino no se define como la ausencia de enfermedad, sino más bien, como un estado de ajuste, o un estado de equilibrio [el cual] es el resultado de una triple relación, interactuante y reciprocada entre el hombre, la naturaleza, el grupo social y sus dioses» (pp. 16-17).

La enfermedad en el mundo andino estaría definida a partir del desequilibrio entre la relación del hombre con su grupo social, la naturaleza y, además, sus creencias religiosas. Por tanto, la medicina tradicional, que suele recrearse en el espacio andino o rural, mediante el uso de la herbolaria y los rituales busca restaurar el equilibrio perdido. Como refiere Cáceres (1988) cuando dice que:

«[...] la práctica ritual curativa que usa el curandero está constituida por elementos religiosos, simbólicos y culturales en general [...]. Estos son mecanismos que están destinados a restituir el equilibrio perdido, equilibrio que se da en las relaciones Hombre-Naturaleza, HombreDioses, Hombre-Hombre» (p. 112).

Para ejemplificar estos postulados, se exponen a continuación algunas concepciones sobre la enfermedad, salud y sanación en Tupe y, cómo se interrelaciona las prácticas médicas modernas con las tradicionales. 


\section{LAS ENFERMEDADES}

Los pobladores de Tupe reconocen que las enfermedades son causadas a partir de tres niveles de intervención que se superponen e imbrican. Por un lado, se asume que la enfermedad o dolencia son causadas por elementos externos al organismo humano, esto hace que se padezca disfunciones corporales, y que son reflejados por dolores, fiebres, mareos, vómitos, entre otros. Por otro lado, se considera que son producto de causas físicas y observables, como golpes o fracturas, que por lo general suelen darse en el trabajo diario. Finalmente, también se asume que las enfermedades pueden estar causadas por elementos sobrenaturales o mágicas. Dentro de ellas, se tiene las que ocasionan los lugares sacralizados de la geografía tupina, como los «cerros», «puquios» o los «espíritus», como las «almas», «duendes»; y también, por los maleficios, conocidos como «brujería» o «daño» efectuados por personas de la misma localidad ${ }^{13}$.

Estas formas de entender a los orígenes de la enfermedad no son excluyentes entre sí. Al contrario, suelen entrar en una relación dialógica, en donde el individuo va asumiendo varias interpretaciones sobre las causas de la enfermedad, según las características y el tiempo que va tomando. Así, el poblador tupino concilia varias formas de entender a la enfermedad desde las tres causas descritas (infecciones, golpes o maleficios), remarcando que en el medio rural contemporáneo no solo se entiende a la enfermedad desde puntos de vista biológicos, sino también culturales: «La definición que un andino hace de su cuerpo no responde solamente a una unidad meramente biológica, sino [...] trasciende al mismo cuerpo y se prolonga en su cultura; por ello el hombre no sólo es su cuerpo, sino también su manera de pensar, su religión y su cosmovisión» (Cáceres 1988: 113).

\section{LAS CURACIONES}

El poblador tupino cuando se queja de dolencias o malestares corporales, tiene dos frentes de curación. Puede acudir al Puesto de Salud y al personal que atiende, para buscar medicamentos que alivien los males; o puede recurrir a las formas curativas a partir de la medicina tradicional de la localidad, el cual está compuesto a partir de los conocimientos sobre las plantas, hierbas y ritos ${ }^{14}$ :

«Gurguniche [cerro frente a Tupe] es malo, te toca, te coge. Un señor que se fue por ahí y se lavó en el puquio y en la tarde se volvió loco. Él decía que escuchaba en su oído que alguien lo llamaba y lo perseguía. Le pasaron el cuy y huevo, lo enterraron al cuy en el mismo lugar del cerro y se curó» ${ }^{15}$.

No se encuentra que en Tupe haya una divergencia entre la medicina moderna, otorgada por el Puesto de Salud, y la tradicional. Por el contrario, ambos constituyen recursos importantes que se utilizan para enfrentar a las enfermedades y males corporales dentro de un contexto donde existe un gran déficit de cobertura de salud por el Estado. Así, en el tratamiento de las dolencias son auxiliados por remedios y técnicas de ambas medicinas, dependiendo de la gravedad del enfermo y de las formas cómo se está entendiendo los orígenes de la enfermedad. Cuando no se encuentra mejoría con los medicamentos modernos y el mal persiste, se suele recurrir a los ritos y pagos a la tierra o divinidades tradicionales.

13 Rosalía Ávalos (1951) mencionaba sobre la enfermedad en Tupe: «[...]. Generalmente el concepto que tienen de la enfermedad es que proviene de frío, de calor, o de un mal aire. Las ideas sobre contagio, infección y enfermedades hereditarias son algo vagas en los de mayores conocimientos y desconocidos por el resto» (p. 96). Actualmente, ya se considera que la enfermedad puede estar causado producto de contagio de algún virus o bacteria.

14 Se tiene testimonio que desde la década del 50 se empieza a considerar a la medicina moderna como forma adicional de curación entre los tupinos. Como señala Ávalos (1951) cuando dice que: «[...]. Actualmente la gente comienza a perder la confianza en sus recursos tradicionales y lentamente se infiltra la medicina moderna» (p. 97).

15 Entrevista a poblador, Tupe. 2008. 
Una de las formas tradicionales es el empleo de las plantas para tratar males respiratorios. Si bien estos pueden ser tratados con analgésicos suministrados por el puesto de salud y o adquiridos en las bodegas del pueblo, finalmente se tratan con infusiones de plantas. Así, una forma de emplearlas es con el llamado "quemadito», que es una poción que combina eucalipto, huamanripa, ajos, limón y una pequeña cantidad de alcohol. Es muy común en el pueblo su preparación pues hay una fuerte confianza que ayuda a curar dichos males.

Además del conocimiento de las plantas, se ha encontrado otros conocimientos respecto a curaciones. Se recogió durante el trabajo de campo, un testimonio de la enfermera quien cuenta que tuvo un inconveniente para el descenso de la placenta de una mujer que acaba de dar a luz a su bebé. La enfermera mencionó que pese a haberle suministrado inyecciones la placenta no descendía, hasta que una vecina del pueblo puso resolver esta situación mediante un tratamiento tradicional que suele aplicar en estos casos:

«[...] Y le digo a la familia pero ellos no querían [trasladarla a Catahuasi] porque iban hacerle a su forma tradicional, con sus hierbas y frotaciones. Luego a la mañana, la mujer seguía con el dolor y la placenta no le descendía hasta que llegaron unos enfermeros de Catahuasi y estaban preparándola para bajarla a Catahuasi, hasta que llamaron a una señora que es partera [...], ella en un rato hizo que baje la placenta. Ni con pastillas ni con ampollas pude hacer que baje la placenta y ella al toque, con no sé qué método lo hizo. Luego de eso le di sus antibióticos por si venía alguna infección[...] ${ }^{16} »$.

\section{RITUALES DE SANACIÓN}

Las enfermedades también suelen ser aliviadas mediante las prácticas rituálicas acudiendo a algunas personas con cierto grado de conocimiento. Si bien en Tupe no existen especialistas como los "yatiris» aymaras, sí se reconoce la existencia de los «curiosos» quienes son los que realizan las prácticas rituálicas ${ }^{17}$. Estas formas de curación tienen un fuerte arraigo cultural e histórico del pueblo de Tupe y, también, refleja una deficiente cobertura del sistema de salud para la población rural. A continuación se describe un caso que se recogió durante el trabajo de campo, donde se aprecia cómo se va asumiendo las formas de interpretar a la enfermedad y su curación.

A fines del año 2007, un miembro de una familia del pueblo de Tupe padecía fuertes dolores musculares en ambos brazos, lo que imposibilitaba que se desplace con normalidad para realizar sus actividades cotidianas en el trabajo y en el hogar. Existía cierto misterio respecto al origen de los dolores que padecía. Sus familiares decían que aparecieron de pronto y sin síntoma alguno. Luego se atribuyó que la persona sufrió un fuerte golpe producto de una caída en la chacra, mientras fue a amarrar su ganado. Y finalmente, se pensó que fue el cerro quien «tocó» y enfermó a la persona luego que se quedara dormida en la chacra.

Sus familiares le suministraron analgésicos para contrarrestar el dolor, los que eran adquiridos en las bodegas del pueblo, pues por estas fechas el Puesto de Salud se encontraba cerrado al no tener personal técnico que pudiera atender. Algunos vecinos, familiares y las madres religiosas, que por esas fechas estuvieron en Tupe, le proporcionaban ungüentos para el dolor. Pese a emplear los medicamentos el dolor no cedía y, al contrario, se incrementaba cada día más. Luego se empleó gran cantidad de hojas de ortiga para frotar las extremidades y menguar el dolor. Al principio el dolor cedía,

16 Entrevista. Técnica en enfermería, Tupe. 2008.

17 Al respecto de especialistas, Bautista (2010b: 222-223) menciona que en Tupe existe el personaje llamado Askyiri, quienes eran individuos que no siendo brujos, ni chamanes, son los encargados de adivinar e interpretar los rituales, como los que se producen en la herranza, dado su poder y vinculación con lo sobrenatural, y con la religión católica. Pese a ello, durante mis indagaciones sobre los especialistas, no encontré mención a tal personaje. Todos los pobladores con quienes pude conversar y entrevistar solo manifestaban la existencia de «curiosos». 
pero al cabo de unos días volvió cada vez más fuerte, llegando a utilizarse tanto de día como de noche, y al cabo de unos días ya fue totalmente inútil pues el dolor continuaba.

Tras varias semanas padeciendo los dolores, la enferma y sus familiares empezaron a dar por sentado que fue el cerro quien provocó la dolencia al «tocarla». Por ello, se asumió necesario realizar un rito como forma de pago y curación al cerro. Se comunicó a un vecino y amigo de la familia, un llamado "curioso», de quien se decía que conocía sobre los rituales y pagos a la tierra y al cerro en caso de encantamientos o enfermedades. Este «curioso» no lucraba con dicho conocimiento, sino que lo brindaba en casos especiales, como el que describimos. La forma como realizó el ritual es de una manera bastante sencilla y práctica. Colocó maíz blanco molido sobre un plato, en donde lo mezcló con alcohol y hojas de coca. Luego rezó en jaqaru y pasó el recipiente por todo el cuerpo de la enferma, sobre todo por la parte doliente, y dirigiéndose luego a media noche al lugar del supuesto encantamiento, arrojó el contenido del recipiente pidiéndole al cerro que haga desaparecer los dolores y restablezca a la enferma. Este ritual se repitió en dos oportunidades, sin encontrar beneficio alguno, pues el dolor y el malestar general continuaron.

Los familiares y la enferma decían si no se conseguía la curación mediante el pago al cerro, se debía a que el origen de la dolencia estaba ocasionado por la «brujería» o el «maleficio». Y así sucedió. Al continuar los dolores, la concepción del origen de la enfermedad cambió y se concluyó en la familia que alguna persona del pueblo les había hecho el «daño». Por lo tanto, la curación tendría que darse mediante la intervención de un «especialista» de fuera de Tupe. Decidieron llevar a la enferma donde un curandero en Cañete, quien buscaría el origen del mal y confirmaría si efectivamente obedecía a un «daño» o era una enfermedad que debería tratarse con la medicina moderna. El «especialista» de Cañete concluyó que efectivamente la enferma había sido objeto de un maleficio de un vecino de Tupe. Realizó varias curaciones con plantas y oraciones y, a la vez, la enferma fue llevada a un médico en Lima quien le diagnosticó que padecía artrosis.

Resulta interesante encontrar, en el caso descrito, que tanto la familia como la enferma daban por hecho que el verdadero origen del malestar en sus extremidades era la «bujería», a pesar de contar con las opiniones de un médico de Lima. En visitas posteriores a Tupe y al hablar con la enferma, esta refería que si bien le habían diagnosticado artrosis y utilizaba algunos medicamentos que le habían sido prescritos, ella dejaba sentado que sus dolores obedecían a maleficios hechos por algún vecino del pueblo. Por ello, tenía que seguir curándose con el «especialista» en Cañete.

\section{LO TRADICIONAL Y LO MODERNO EN LA CURACIÓN}

Las interrelaciones entre lo tradicional y moderno en las prácticas curativas en Tupe, se puede sintetizar en el siguiente recuadro (Tabla 2). Se aprecia que la enfermedad y curación están en relación a cómo se las entiende, por ello para los aspectos «mágicos» o «sobrenaturales», la medicina moderna no tiene mayor intervención en la sanación.

Tabla 2: Enfermedad y Formas de curación en Tupe

\begin{tabular}{lll}
\hline \multirow{2}{*}{ Enfermedad / Dolencia } & \multicolumn{2}{c}{ Formas de curación } \\
\cline { 2 - 3 } $\begin{array}{l}\text { Gripe, dolor de cabeza, de muela } \\
\text { Torceduras, fracturas, golpes corpo- }\end{array}$ & Medicina Tradicional & Medicina Moderna \\
rales & Emplastos, frotaciones & $\begin{array}{l}\text { Pastillas } \\
\text { güentos }\end{array}$ \\
$\begin{array}{l}\text { Males de «ojo», «susto», «frío», } \\
\text { «Cerro». }\end{array}$ & Rezo, ritual & ---- \\
«Daño», «brujería», «hechizo». & Rituales & ---- \\
\hline
\end{tabular}

Fuente: Elaboración propia. 
Esto ocasiona que desde el Puesto de Salud se tenga la percepción de que muchas de las curaciones con plantas medicinales son causantes de retrasos en la atención médica moderna. Se reconoce que los pobladores acuden primero a sus prácticas curativas tradicionales. Desde luego esto también está en función al tipo de dolencia, pues como se ha descrito líneas arriba se utilizan analgésicos antes de acudir a las plantas o rituales. De todos modos, la enfermera refiere que:

«La gente se cura primero con sus hierbas[...] dos días, 'señorita le he dado hierba tal y tal', empieza más fuerte la enfermedad, ya que no le funciona las hierbas acuden a la Posta. La mayoría se atiende pero se quejan por las medicinas, recurren a la Posta cuando el niño está mal, y dicen 'jarabe de la posta no hace nada'. Ellos lo tienen [al enfermo] dos, tres días con sus hierbas, luego recién vienen ${ }^{18} »$.

El ausentismo que describe la enfermera es entendido bajo razones culturales, lo que implica tener valoraciones negativas hacia los entornos locales de la población, básicamente referidas hacia la agricultura y ganadería. Así, para los que representan al Puesto de Salud, el poblador tupino valora más a su ganado que a su propia persona. Como refiere en el siguiente testimonio:

«La gente de aquí no se quieren así mismo, no se quieren, vienen casi dos o tres para pastillas, el resto guardados, prefieren sus animales, las ampollas para sus animales, pero que le digas para su niño, nada. Dan la vida para sus vacas ${ }^{19}{ }$.

Si siguiéramos dicho argumento, se podría postular erróneamente que es por las lógicas culturales locales que las personas no acuden a los servicios médicos, trasladando la responsabilidad a los pobladores y no a las instituciones como el Estado, el Ministerio de Salud y el mismo Puesto de Salud. Y no situando, además, que mucho de este ausentismo se debe a las ineficacias e insuficiencias de los servicios que se brindan.

Finalmente, podríamos decir que la relación que existe entre la medicina llamada moderna y tradicional, trae al debate un problema social muy fuerte e importante para los sectores rurales del país: la cobertura del sistema de salud. Ello, como se ha visto a lo largo del texto, acarrea problemas reales de ciudadanía, pues se tiene que muchas poblaciones, como el caso de Tupe, están muy lejos de poseer un real y eficiente Puesto de Salud que satisfaga a sus necesidades. También permite ver que desde el servicio oficial de salud hay una inexistente articulación hacia los conocimientos y técnicas tradicionales de curación. No se integra los conocimientos sobre la herbolaria y demás saberes compartidos por los pobladores de Tupe. Todo ello genera que se aprecie a los servicios del Puesto de Salud como insuficientes y poco confiables, en donde las prácticas curativas brindadas resultan ineficaces, a pesar de los esfuerzos que se realiza para superar al poco recurso humano y la poca infraestructura con la que se cuenta.

Por ello, más allá de presentar las concepciones de la enfermedad y las formas de curación en Tupe como algo «exótico», «folclórico» o como una «supervivencia» del pasado prehispánico, se ha tenido el objetivo de presentarlas como una práctica cultural, que son utilizadas para hacer frente a una situación de exclusión social actual. Situación que es compartida lamentablemente por muchas otras poblaciones rurales del país, donde se sigue viviendo bajo exclusiones en cuanto a la salud, la educación, la seguridad, entre otros. En el caso descrito, la existencia de un precario Puesto de Salud, con poco personal, limitado equipo y atenciones deficientes, nos invita a reflexionar los niveles de ciudadanía que existen en el país y, sobre todo, respecto a las poblaciones rurales como Tupe. 


\section{CONCLUSIONES}

Los pobladores de Tupe, pese a contar con prácticas tradicionales de organización y producción se encuentra inserta dentro de dinámicas sociales, económicas, culturales y políticas que van más allá del espacio físico del distrito y la comunidad. Es a partir de estas interrelaciones entre lo local y lo global que actualmente se tiene que conceptuar a este grupo humano. Dejar de analizarlos como una comunidad «pura» $\mathrm{y}$ «detenida» en el tiempo, sino otorgándoles contemporaneidad. Una forma de hacerlo es incluir en los análisis las situaciones actuales en la que vive la gente, como los niveles de pobreza, de exclusión y peticiones de reconocimientos de derechos, como la lucha por la Educación Intercultural Bilingüe.

Respecto al tema de estudio, el sistema general de salud que funciona en Tupe está definido a partir de dos formas de curación no excluyentes. Se tiene, por una parte, al Puesto de Salud con su escaso personal y pocos servicios, los cuales resultan insuficientes para la demanda de la población; y por otra parte, se cuenta con la medicina tradicional, especialmente con el empleo de plantas, hierbas y ritos de curación. Estos dos sistemas médicos que se presenta en la localidad obedece a que las enfermedades se conciben a partir de tres aspectos: las razones biológicas (virus, bacterias), razones objetivas (golpes, el frío, el calor) y maleficios («brujería» o «daño»). Para la curación se recurre a los dos tipos de medicinas, dependiendo de las razones por la que se cree estar enfermo. Así, en algunos casos se acude a los medicamentos modernos (pastillas, inyecciones, ungüentos), en otros casos a las plantas médicas y los ritos de curación, y en casos extremos a curanderos fuera del pueblo. Esto demuestra que desde el individuo existe una relación constante entre ambas medicinas que las emplea en cada momento de la enfermedad. Por el contrario, desde el Puesto de Salud dicha relación es más bien tensionada, pues se asume que las creencias y prácticas tradicionales son trabas para la adecuada atención.

En suma, la presencia de la medicina tradicional en comunidades campesinas y rurales muestra que aún se poseen dichos conocimientos, los cuales son empleados en sus vidas cotidianas para restablecer el estado de salud de sus miembros. Pero también, muestra que el individuo, en este caso el poblador de Tupe, utiliza los conocimientos culturales de su localidad como mecanismos o recursos para enfrentar a la limitada cobertura de salud que el Estado peruano imparte a las poblaciones rurales. Buscando con ello, enfrentar y tratar de solucionar uno de los mayores problemas que se presenta en todo los grupos humanos: la preservación de la salud y el tratamiento de las enfermedades.

\section{Agradecimientos}

Dejo constancia mi agradecimiento al profesor Ananías Huamán Talavera, quien leyó e hizo valiosas observaciones al primer borrador de este texto, hace ya varios años atrás. También, al profesor Román Robles Mendoza, quien siempre gentilmente leyó las numerosas versiones del trabajo. Por otra parte, agradezco a los pobladores de Tupe, quienes en mis numerosos viajes entre el año 2007 y 2008, me han brindado el mayor de los apoyos para toda indagación antropológica. Especialmente agradezco a la señora Teodolinda Sanabria, la profesora Shumay Sanabria, así como a Robinson Ordoñez Payano y, sobre todo, a César Payano, su esposa Elodina Casas y sus hijos María y Willy, quienes desde fines del año 2007, me acogieron como un miembro más de su familia.

\section{BiBLIOGRAFÍA}

ÁVALOS, Rosalía

1951 El ciclo vital en la comunidad de Tupe. Tesis. Lima: UNMSM, Facultad de Letras.

BAUTISTA, Dimas

2010a Mark Qillqa TUPE. Estudio histórico-cultural de Marka-Tupe. Pueblo de habla Jaqaru Año 750 d.C. - 2010. Lima: UNMSM.

2010 b «Arte vivencial de Marka - Tupe». Folklore. Arte, cultura y sociedad. Revista del Centro Universitario de Folklore. 1(3): 215-236, diciembre. Lima: UNMSM. 
CABIESES, Fernando

1993 Apuntes de Medicina Tradicional. La racionalización de lo irracional. Lima: CONCYTEC.

1974 Dioses y Enfermedades del Antiguo Perú. Lima: Artegraf.

CÁCERES, Efraín

1988 Si crees, los Apus te curan. Medicina andina e identidad cultural. Cusco: Centro de Medicina Andina.

CERRATE, Ema y Óscar TOVAR

1954 «Informe Preliminar del Estudio Botánico de Tupe». Revista del Museo Nacional. 23: 140-161. Lima.

DELGADO, Carmen

1965 Religión y Magia en Tupe (Yauyos). Museo de la Cultura Peruana. Serie Tesis Antropológicas 2. Lima.

DELGADO SÚMAR, Hugo E.

1991 Los especialistas en la medicina tradicional. Lima: Ministerio de Salud. Instituto Nacional de Medicina Tradicional. Dirección General de Investigación y Tecnología

$\mathrm{S} / \mathrm{f} \quad$ Salud y enfermedad en el mundo andino. Lima: Ministerio de Salud. Instituto Nacional de Medicina Tradicional. Dirección General de Investigación y Tecnología.

HARDMAN, Martha

1983 Jaqaru: compendio de estructura fonológica y morfológica. Lima: IEP.

MATOS, Alejandro

1984 «Tupe, pueblo tradicional de la provincia de Yauyos». Boletín de Lima 36(6): 57-68, noviembre. Lima.

MATOS, José

1956 Yauyos, Tupe y el Idioma Kauke. Lima, UNMSM. Instituto de Etnología, № 12.

1951 La Ganadería en la Comunidad de Tupe. Lima. UNMSM. Instituto de Etnología. № 2.

1949 Tupe, una comunidad del área cultural del Kauke en el Perú. Geografía y Economía. Tesis. Lima. UNMSM. Facultad de Letras.

MONTALVO, Dora.

2007 Conocimiento médico en el Perú antiguo. Vigencia actual. Contribución a su estudio. Lima: DAVISA.

RAMÍREZ TREBEJO, Andrés

2012 «Entre la ilusión y la desesperanza. Los sinuosos caminos hacia una educación intercultural bilingüe en Tupe, una comunidad jaqaru hablante del Perú». En: Investigaciones Sociales 6(29): 197-208. Revista del Instituto de Investigaciones Histórico Sociales, UNMSM.

2010 Democracia y participación en espacios rurales. Un estudio en Tupe, una comunidad del jaqaru en el Perú. Tesis para optar el título de licenciado en Antropología. Lima. UNMSM.

SÁNCHEZ, Ricardo y Rodolfo SÁNCHEZ

2009 Medicina Tradicional Andina. Planteamientos y aproximaciones. Cusco: Centro de Estudios Regionales Andinos Bartolomé de Las Casas y Centro de Medicina Andina.

VALCÁRCEL, Luis E.

1953 «El conocimiento científico de los Pueblos del Perú: Resumen de las Investigaciones Etnológicas realizadas en los últimos años». Revista del Museo Nacional. Tomo XXII: 3-16, Lima.

VALDIZÁN, Hermilio y Ángel, MALDONADO

1985 La Medicina popular peruana. Lima: Consejo Indio de Sudamérica, 2da edición.

VETTER PARODI, Luisa y Martin MACKAY

2008 «Tupe: un pueblo detenido en el tiempo». Arqueología y Sociedad 19: 265-292. Museo de Arqueología y Antropología, UNMSM.

ZULUAGA, Germán

2009 «Reflexiones para un diálogo entre los sistemas tradicionales de salud y la medicina occidental». En: R. Sánchez y R. Sánchez (eds.) Medicina tradicional andina. Planteamientos y aproximaciones, Centro de Estudios Regionales Andinos Bartolomé de Las Casas (CBC) y Centro de Medicina Andina. Cusco. 


\title{
AROUEOLOGÍA Y SOCIEDAD
}

№ 26, 2013: $385-394$

ISSN: 0254-8062

RECIBIDO: 30 / MAR. / 2013

ACEPTADO: 15 / MAY. / 2013

\section{EL CULTO A LAS YLLAS EN HUÁNUCO PAMPA: ENTRE LA LUNAY EL PUOUIAL}

\author{
CARLO ORDÓÑEZ INGA \\ DiRECTOR DEL PROYECTO dE INVESTIGACIÓN HuÁNUCO PAMPA, Ministerio de CULTURA \\ carlojoseordonez@gmail.com
}

\section{RESUMEN}

En este artículo se presentan evidencias de un culto ancestral, como fue el relacionado a las yllas, entre algunas familias ubicadas en los alrededores de Huánuco Pampa. El registro fue realizado en los años 2007 y 2012, durante la ejecución del Proyecto de Investigación Huánuco Pampa - Programa Qhapaq Ñan del Ministerio de Cultura.

La metodología para esta investigación consistió en entrevistas a los actores principales, poseedores de yllas, y la posterior contrastación con la revisión de información etnohistórica, a fin de demostrar cierta continuidad de esta práctica ritual relacionada durante la época inca con la crianza de camélidos y el día de hoy con la de ganado bovino y ovino.

Palabras Clave: Huánuco Pampa, ylla, piedra

\section{AbSTRACT}

This article shows evidences of an ancestral cult related with the yllas found between some families located around the Huanuco Pampa site. The record was realized in 2007 and 2012, during the execution of the project Huanuco Pampa - Programa Qhapaq Nan by the Ministry of Culture.

The methodology of this research consisted of interviewing to the community, who had the yllas, and then the information collected was contrasted with the revision of the ethno-historical data, in order to demonstrate some continuity of this ritual related with the husbandry of camelids at the incas time and the husbandry of bovines and ovines at present day.

KeYwords: Huanuco Pampa, ylla, stone.

\section{INTRODUCCIÓN}

Algunas fuentes etnohistóricas del siglo XVI nos informan sobre la presencia de grandes recuas de camélidos en los alrededores de Huánuco Pampa, lo cual resulta ser un dato interesante, toda vez, que dicha especie ha desaparecido de la zona actualmente.

Al respecto, en un documento escrito en 1533 por Miguel de Estete, se narra, entre otros hechos, la llegada de Hernando Pizarro a Guanaco (Huánuco Pampa), describiéndose brevemente y con algu- 
nos detalles este centro administrativo-religioso ${ }^{1}$, refiriendo además la abundancia de camélidos en la zona, tal y como sigue a continuación: «Sábado veynte e ocho del mes de março por la mañana partió el dicho capitán deste pueblo e fué a dormir a otro que se dice Guanaco, que serán cinco leguas de camino, lo más de los enlozado y empedrado por mucha orden, y hechas sus acequias por dó corre el agua. Dicen ques hecho por causa de las muchas nieves, que en cierto tiempo del año caen por aquella tierra ques cosa harto de ver este edificio. Es grand pueblo este de Guanaco, y está en un valle cercado de sierras no muy ásperas: tiene este valle tres leguas de circunferencia, e por la una parte, viniendo a este pueblo de Caxamalca, hay una grand subida e agra mucho. En aqueste pueblo hicieron al capitán buen rescebimiento e dieron todo lo que fue menester para el servicio de los españoles: e dos días que allídescansaron le hicieron muchas fiestas. Llámase el señor principal de aquel pueblo Pumahanchis: es pueblo de muchos ganados, e tiene otros muchos pueblos a él sujetos.» (Miguel de Estete 1917[1533]: 98-99).

Años más tarde, tan sólo veinte años después, el cronista Cieza de León revelaría la grave disminución que sufrió la población de camélidos en los alrededores de Huánuco Pampa, narrando con ciertos matices de añoranza y preocupación que: «Había en los tiempos pasados tan gran cantidad de ganado de ovejas y carneros, que no tienen cuenta; mas las guerras lo acabaron en tanta manera, que desta muchedumbre que habia ha quedado tan poco, que si no lo guardan los naturales para hacer sus ropas y vestidos de su lana, se verán en trabajo.» (Pedro Cieza de León 1928[1553]: 429).

Entonces, considerando que, en épocas prehispánicas y en los primeros años de la conquista, existió en las proximidades de Huánuco Pampa un gran número de camélidos, se puede presumir, en base a los datos etnográficos de otras regiones (Flores 1977, Condori y Gow 1982; Taipe 1991; Delgado de Thays 1965), que los habitantes de este centro administrativo-religioso inka, dedicados, entre otras actividades, al pastoreo, desarrollaron creencias mágico-religiosas asociadas a su crianza, como es el caso del culto a las yllas.

Por lo tanto, ¿en los alrededores de la actual zona arqueológica de Huánuco Pampa, antigua capital provincial inka, será posible encontrar familias que aún conserven la creencia en las yllas asociadas al aumento y protección del ganado? A modo de hipótesis se puede plantear su existencia, toda vez, que hoy en día, como en el pasado, las familias de las comunidades alto andinas conservan las mismas preocupaciones por la producción y reproducción, así como la disminución de los animales domésticos (Taipe 1991: 17-18), por ello estas prácticas netamente andinas, aunque alteradas por la religión occidental, aún subsisten después de muchos siglos en esta zona.

\section{Alcances del ÁREA DE ESTUdio}

Esta investigación se desarrolla dentro de los territorios de la comunidad campesina de Agüamiro, ubicada en los Andes centrales del Perú, en el departamento de Huánuco, provincia de Dos de Mayo, distrito de La Unión. Sus terrenos se extienden sobre gran parte de la altiplanicie conocida entre los pobladores locales como «la pampa», a $3600 \mathrm{msnm}$ aproximadamente. La zona posee un clima frío y húmedo, con una temperatura promedio que fluctúa entre los $9^{\circ} \mathrm{C}$ y $11^{\circ} \mathrm{C}$ como media anual. $\mathrm{Su}$ topografía es predominantemente plana y con suaves relieves, presentando además una vegetación caracterizada por gramíneas de estepa, arbustos dispersos y con la presencia de algunos cursos de agua que atraviesan la superficie.

La población de la comunidad campesina de Agüamiro tiene como actividad económica principal la ganadería familiar, caracterizándose por practicar básicamente una economía de autoconsumo de los productos derivados (leche, carne y lana). Asimismo, el ganado se alimenta sin restricciones de los escasos pastizales de la comunidad y el agua es un recurso que no abunda. Bajo estas condiciones las personas aún conservan y se aferran a ideologías y creencias religiosas relacionadas a la ganadería,

1 En este documento se describe por primera vez Huánuco Pampa, llamado Guanaco por aquel cronista. 


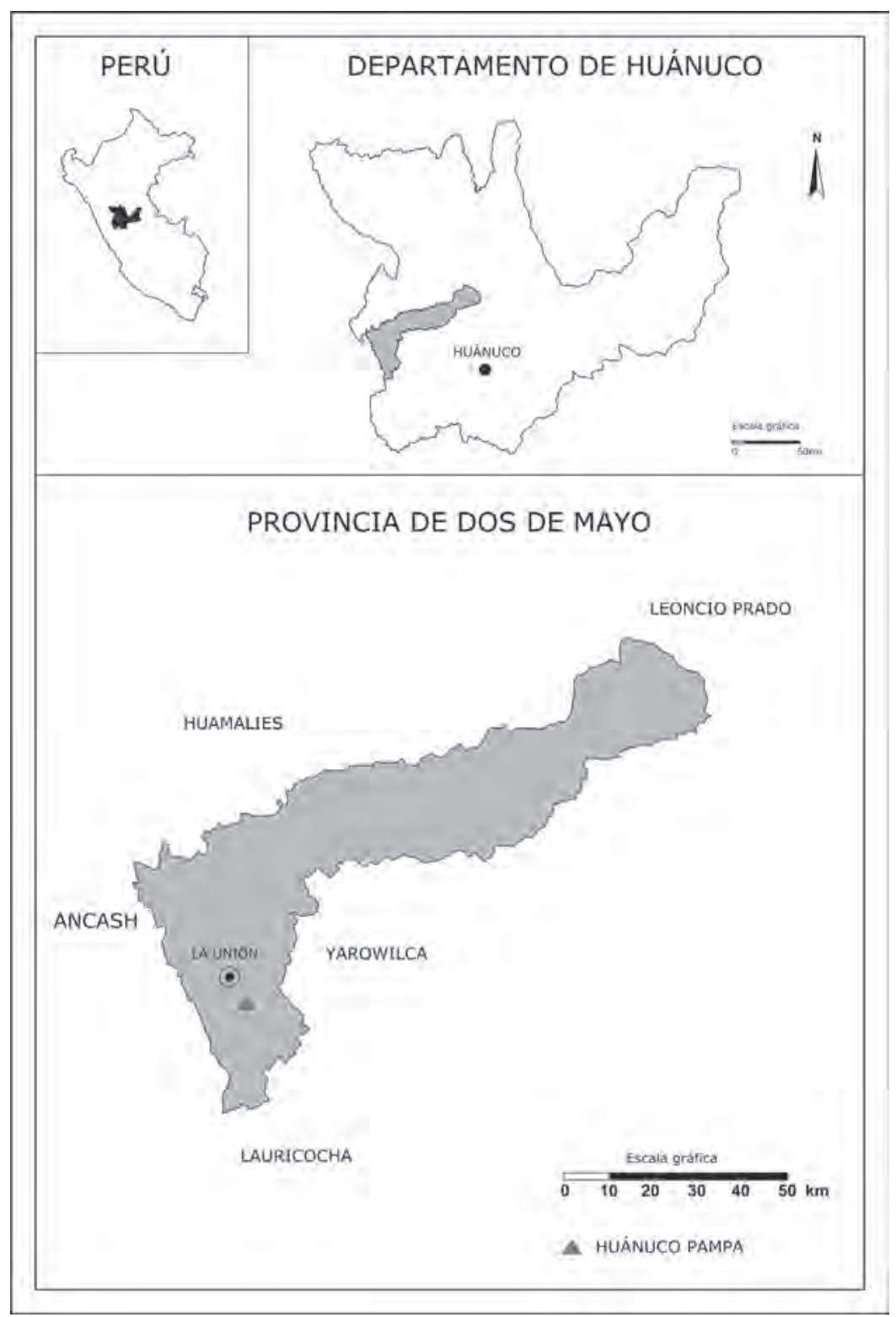

Figura 1. Ubicación de la comunidad campesina de Agüamiro.

cuyos orígenes se remontan, al menos para el caso de la Ylla, a épocas prehispánicas. Evidencias de este culto también fueron registradas en otras comunidades campesinas cercanas como: Huaricashash, Estanque, Isco, Taparaco, Víctor Raúl, que, al igual que la Comunidad Campesina de Agüamiro, se encuentran a la vera del camino inca o incanani en el quechua local.

Es al interior de los terrenos de la comunidad campesina de Agüamiro que se encuentra Huánuco Pampa, ciudad inca que cumplió las funciones de centro administrativo, político y religioso, la cual tuvo bajo su control las etnias locales de la región, como los Chupaychus, Yachas, Wamalli, entre otras (Morris y Covey 2003). Este centro urbano inca es lo más resaltante del lugar, aunque no es la única evidencia arqueológica de toda la pampa, toda vez, que existen dispersos otros monumentos arqueo- 
lógicos con ocupaciones prehispánicas que esperan ser debidamente estudiados, ampliando de esta manera el panorama de investigación ${ }^{2}$.

\section{LAS YLLAS}

Las yllas, que pueden ser consideradas un tipo de conopas, son amuletos familiares de piedra que representan animales domésticos y cuya posesión y veneración garantiza la reproducción y protección de los mismos, la antigua adoración que se cultiva a estas piedras puede ser rastreada en uno de los escritos que se conservan en el Archivo Romano de la Compañía de Jesús, donde se lee lo siguiente: "Y a este modo un indio hizo otro tanto de una guaca llamada / illa. q. tenia en su casa, en la q.l. tenia puesto su corazón adorándola y reverenciandola como / a dios esta era vna piedra [...]» (Cabredo 1999[1601]: 244). ${ }^{3}$

En los alrededores de Huánuco Pampa hemos identificado y registrado yllas bajo la posesión de algunas familias, las cuales se caracterizan por ser unas piedras con algunos rasgos zoomorfos, de dimensiones pequeñas (10 x $5 \mathrm{~cm}$ aproximadamente), bastante toscas que, a diferencia de lo que informó en su momento Flores Ochoa (1977: 216), son sin esculpir. Sin embargo también poseen facultades mágico-sagradas, que brindan seguridad y bienestar a los animales de las personas que la poseen.

Según los comuneros de «la pampa», las yllas pueden simbolizar a cualquier animal doméstico, pero principalmente informan sobre la representación de vacas, toros y ovejas, siendo estos los animales más comunes en el área y más beneficiosos, tal y como aseguró uno de los informantes: «[...] pueden tener la forma de cualquier animal[...] hay vaca, hay ganado, caballo también hay[...]»

Algunos documentos coloniales afirman que el bezoar ${ }^{4}$ era denominado illa llama (Polia 1999: 175), venerándolo de la misma forma que a las yllas. Así se puede leer a continuación en un documento de finales del siglo XVI: "Y ansimismo en los ganados de la tierra que llaman llamas, se hallan unas piedras que nosotros llamamos besares, que en alguna[s] dellas hay piedras de grandor y pesso; a éstas las han guardado y guardan donde hay ganados de la tierra y las mochan con much a reverencia llamándolas yllas llamas. He hallándolas en muchas provincias donde tienen ganados y hécholas quemar, porque usan de muchas supersticiones con ellas y crehen que, mochando a esta piedra, ninguna oveja abortará, ni subçederá mal a ninguno de sus ganados ni le dará carache, ques un género de sarna que le da al ganado de la tierra. Y después que nosotros hazemos caso dellas, las guardan, y más las grandes que las pequeñas, que las pe[que]ñas que hallan con facilidad las dan, no saviendo la virtud que tenían. Quemé muchas petacas dellas que descubrí públicamente en plaças de muchas provincias deste obispado» (Albornoz 1989[1582]: 165-166).

Inclusive en una visita realizada a Recuay, exactamente en el ayllu de Hecos, a finales del siglo XVII por Rodrigo Hernández Príncipe, se menciona la existencia de una casa conocida como Illahuasi, en donde guardaban y rendían culto a las piedras besares a cambio de una mayor reproducción de camélidos: "Tenían en veneración la casa de las piedras besares, que llaman Illahuasi ofrecida al Rayo por el aumento de los carneros de la tierra; y tenían depositario para ello.» (Hernández 2003[1622]: 756).

Los datos etnohistóricos son bastante amplios al respecto, mas no es nuestra intención hacer una lista de todos, solo hemos visto conveniente presentar unos cuantos fragmentos con el objetivo

2 Estas evidencias arqueológicas en la pampa fueron reconocidas por el autor los años 2005 y 2007, identificando no solo restos de las escalinatas del camino inca o incanani que ascienden a la pampa en dirección norte-sur, sino también pequeñas plataformas, grandes estructuras de planta circular a modo de corrales, pinturas rupestres y otras posibles qollqas incas, todas fuera del cerco perimétrico que encierra la actual Zona Arqueológica Monumental de Huánuco Pampa.

3 Ylla e Illa se refieren a lo mismo, solo que la primera es el término quechua y la segunda el aymara (Manríquez 1999: 108).

4 Según Mario Polia los bezares / besares / bezoares son enterolitos o concreciones esferoidales formadas por aglomeración de pelos, resinas, entre otras, en el estómago de los auquénidos (Polia 1999: 175). 
de mostrar cuán arraigado se encuentra este culto en las comunidades alto andinas y presentar su vigencia en la comunidad campesina de Agüamiro a pesar del tiempo transcurrido, las campañas de idolatrías y la presencia actual, y cada vez más intensa, de las iglesias evangélicas, las cuales transmiten discursos que van en desmedro de esta creencia ancestral.

\section{EL ENCUENTRO ENTRE LAS YLLAS Y LOS ELEGIDOS}

La manera como ciertas personas encuentran estas yllas es totalmente fortuita, en algunos casos se puede dar mientras se camina por el campo, especialmente por algunas quebradas, siempre de noche y con la luna llena, aunque nos informaron que ciertos comuneros tienen noticias de lugares exactos en donde se hallan estas piedras sagradas y van en su búsqueda. Estos puntos de hallazgo van a ser distintos, dependiendo de la necesidad que se tenga de reproducir rápidamente algún animal y cuya protección se quiera asegurar para los momentos de sequía o escasez ${ }^{5}$, es decir, cada animal tiene un lugar específico en donde se puede hallar su ylla. Y como se dijo, estos siempre se encuentran vinculados a puquiales o fuentes de agua (lugares sagrados o wakas) y a la presencia de la luna, tal y como aseguró un comunero de la pampa: "[...]la ylla sale en los manantiales, en luna llena por la madrugada y es una piedra con forma de animal,[...] sale similar a un animal, si encuentras la ylla aumentan los animales...el ylla se encuentra mayormente en el canto de los puquiales». La mayoría de comuneros que han visto, alguna vez, la aparición de yllas afirman que son animales en miniatura que salen de los puquiales para pastar alrededor, estos son atrapados por los hombres cuando tienen suerte y de inmediato se convierten en piedras que luego son veneradas en secreto por ellos. Pero como se explicará más adelante, también existe la ylla viva que no es otra cosa que un animal con alguna característica destacable y que asegura una reproducción mayor.

Las personas que han encontrado alguna vez en su vida una ylla son admiradas por los demás, porque con ellas «el cerro fue bueno», y les concedió bienestar. Así nos dijo un comunero: «Yo de casualidad he encontrado sino todos tendrían, J. R. ha encontrado en su estancia, si es que la persona muere la ylla se la da a sus hijos. El cerro nos los da como premio cuando somos buenos...todo mundo se admira con lo que tengo, los familiares,[...]».

Sobre esto, Anello Oliva hace varios siglos refería también que las yllas o conopas eran heredades de padres a hijos (Oliva 1895[1631]: 135).

La posesión de una ylla no es común entre las familias de la comunidad y lograr que alguien pueda mostrarla a un extraño requiere sobre todo de mucha confianza, eso nos sucedió a nosotros, inclusive se cree que si alguien que no es de la familia llega a verla, ésta ya no sería tan prodigiosa y perdería su poder protector y reproductor.

A continuación se reproduce la información brindada por R. A., comunero de la pampa, en torno a las consecuencias que afectan a las personas que no cumplen con otorgar sus ofrendas a la ylla: «En el caso que des de salar a tus animales y no les des alguna ofrenda a tu yIla, tus animales se mueren o se pierden, a veces el zorro se lo lleva, porque el zorro también es cerro...por ejemplo si tu has fallado un año y no le das a tu yIla, el zorro se lleva a tu mejor animal, y el zorro se come al mejor. Y si hay problemas en la vecindad la gente te puede hacer daño...y a tu jirka le pueden hacer mal[...] cuando la gente sabe dónde está tu jirka entonces lo mandan destruir...entonces tus animales se empiezan a morir, en la mañana aparecen muertos[...] se lo llevan la gente, desaparecen tus animales[...] entonces si encuentras movido o mal tu jirka de inmediato debes acomodar...y no pasa nada;[...] cada vez que damos de salar a nuestros animales tenemos la costumbre de masticar nuestra coca[...] y le damos a nuestra jirka. La ylla se coloca cerca de donde vives».

5 Esto se da por lo general durante los meses de agosto y setiembre cuando los pastos escasean por la ausencia de lluvias. 


\section{TIPOS DE YLLA}

Según cuentan los comuneros de «la pampa», las yllas pueden conservarse de dos formas: 1) La Ylla de piedra y 2) la Ylla viva.

\section{LA YLLA DE PIEDRA}

En este caso, la ylla es una piedra zoomorfa, como ya se dijo líneas arriba, sin esculpir, cuyas dimensiones varían entre 5 y $10 \mathrm{~cm}$ como promedio aproximadamente, no registrándose de mayores dimensiones. Los colores de estos llamados «amuletos» pueden ser ocre, blanco, y negro.

Estas piedras, a diferencia de otras regiones del Perú, no son talladas por la gente con la forma de algún animal de su rebaño, sino que simplemente la dejan tal y como la encuentran, lo cual no le resta parecido con el tipo de animal que poseen. Uno de los comuneros entrevistados afirmó que: "Se convierte en piedra cuando el cerro no es para ti, no es para su corazón, se convierte en una piedra pero en chiquitito, entonces tú te llevas y lo colocas en un cajoncito y con eso aumenta de un ganado nomás, aumenta en cantidad de ganado. Así también hay». Sobre esto, en un documento del siglo XVII se lee al respecto: «Y en encontrando con algunas piedras en que parecia auerse / estremado la naturaleza dándoles alguna hechura forma / o color estrahordinario las cogían y guadauan y tam/bien los hechizeros las dauan diciendo que quien tuuiese a/aquellas tendría mucha hazienda y ganado dela tierra ques la / riqueza que los indios mas estiman,

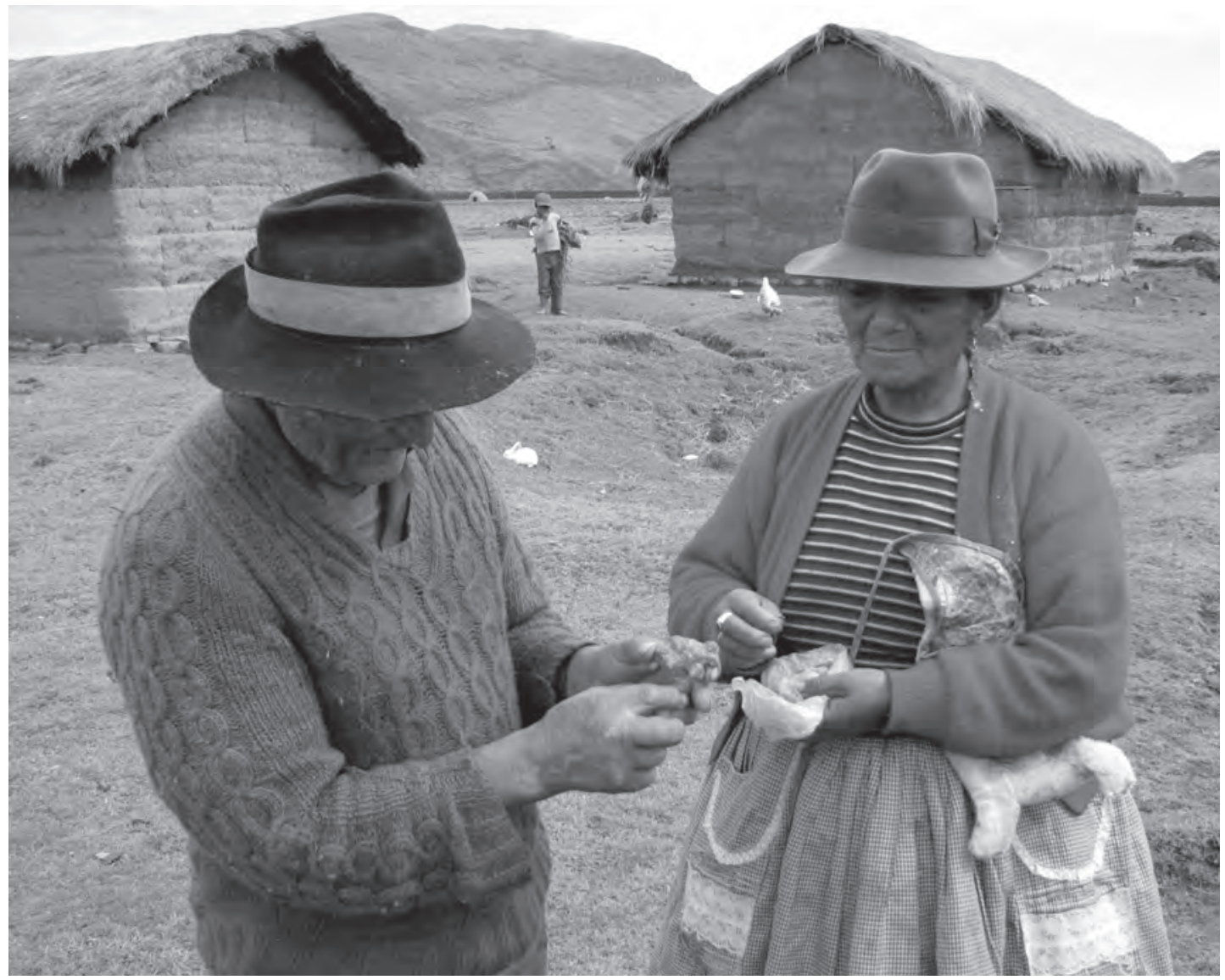

Figura 2. El Sr. Leonardo Tiburcio y su esposa mostrando una de sus yllas. 


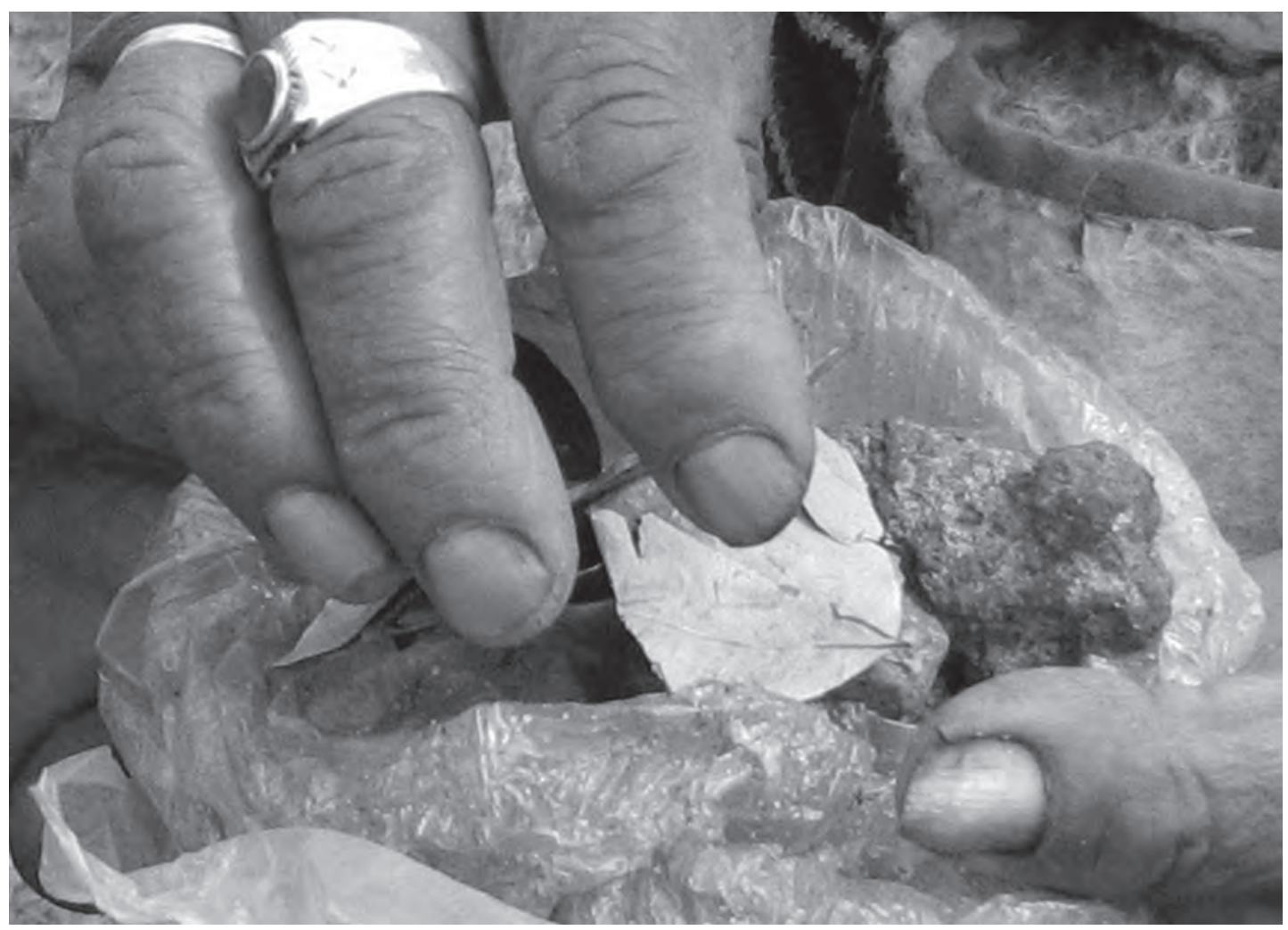

Figura 3. Nótese la ylla con sus ofrendas de hojas de coca y azúcar.

aestas llamauan / illas, y el demonio les tiene tan persuadido esto que en / uiendo que auno sele multiplica el ganado y la hazien/da dizen luego, chay illayoc, que quiere decir aquel tiene ylla / esta tenían en sus casas y la adorauan y sacrificauan de // ( fol 261) la manera que queda dicho cuyes y corderos y tenían muchos / trapillos con poluos amarillos y colorados de llimpi del / azogue y de otras cosas con las cuales embarnizauan / las, illas, y se los fregauan y les soplauan aquellos colores queera / el modo de sacrificalles. Y estauan tam persuadidos a que / aquello era causa de las riquezas que a mucho trabajo / se pueden olos podemos persuadir de la uerdad.» (Ayala 1999[1614]:359).

Una vez que tienen en sus manos la ylla o las yllas, porque en algunos casos no solo se encuentra una sino que también pueden aparecer en pareja, esta es conservada con mucho celo y cuidado, evitando divulgar la noticia. La ylla es colocada dentro de una bolsita de plástico junto con algunas hojas de coca y azúcar de diferentes «tiendas», esta a su vez es guardada al interior de una pequeña caja de cartón que representa el corral y si se lleva los animales a pastar la ylla puede ser trasladada en un wallqui o bolsa de cuero de conejo o carnero con todas sus ofrendas. En otros casos simplemente es colocado en la caja de cartón con las ofrendas ya enumeradas, tal y como contó un comunero de la pampa: «Lo tienen en cajón porque si no escapa y ahíle dan caramelo, azúcar, siete clases de azúcar le dan de diferentes tiendas comprando. Tengo en piedra pero ese es consagrado, no se puede mostrar, sino el cerro es malo, tengo dos[...] un hembra y un macho[...] te pueden castrar.»

\section{LA YLLA VIVA}

Este tipo de ylla se encuentra, también como en el caso anterior, siempre junto a un puquio o manantial cuando hay luna llena y las referencias de sus apariciones no son escasas, muchos comuneros ase- 
guran haber visto alguna vez en su vida grupos de yllas comiendo en los alrededores de los puquiales, aunque no todos han tenido la suerte de atraparlas. Este tipo de ylla destaca por su belleza y tamaño sobre las demás, aunque también los comuneros indicaron, más de una vez, que son identificadas por tener defectuosas algunas partes del cuerpo (la extremidad doblada, los ojos de otro animal, entre otras anomalías). Por consiguiente los rasgos de estas yllas pueden ser sintetizadas de la siguiente manera: 1) Belleza, 2) Tamaño y 3) Defecto.

A continuación se expone textualmente lo que uno de nuestros informantes contó sobre esta clase de ylla: "Este es el pozo, este es el manantial y en épocas de luna llena salen a comer alrededor y a veces un poquito más se alejan y cuando ven gente corren y se meten de nuevo al pozo y como esta estuvo lejos no ha podido entrar y yo le he atajado del pozo y he agarrado mi sombrero y se ha quedado ahí ya no pudo entrar. Ha parido más de 16 o 17 y sus crías nacen natural nomás ya no como su mamá. Cuando uno muere el cerro se lleva la yila, no se le deja al hijo mayor porque él no administra como uno mismo. Es como un contrato, cuando vas a morir se rebela en tu sueño para que lo dejes en el mismo sitio de donde ha salido[...] la misma persona que lo encontró debe dejarlo[...] entonces lo dejas y ahí desaparece». Esta última parte contradice lo señalado por otros comuneros que aseguran que sus yllas son heredadas por sus hijos, sin embargo existen también estos casos.

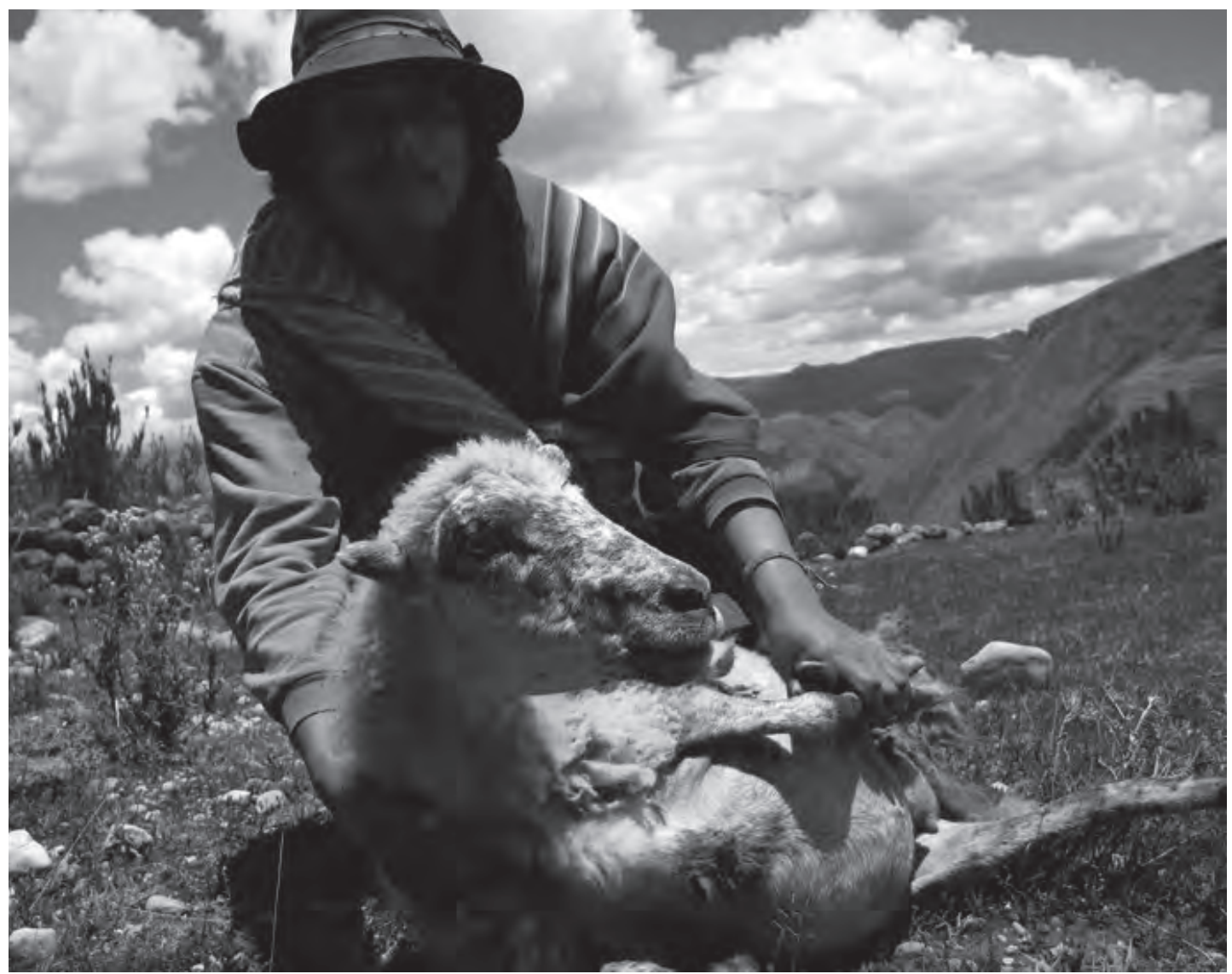

Figura 4. Un comunero de la pampa mostrando una ylla viva, según él esta oveja tenía los ojos de otro animal. 


\section{CONCLUSIONES}

Actualmente en la altiplanicie donde se emplaza la ciudad inca de Huánuco Pampa no existen camélidos, pero de acuerdo a la información etnohistórica se colige su existencia y crianza en épocas prehispánicas y poco tiempo después de la llegada de los españoles, lo cual implicó el desarrollo de creencias mágico-religiosas asociadas al pastoreo.

Para finales del siglo XVI la población de camélidos sufrió una disminución alarmante en la pampa, sin embargo ya para entonces los primeros españoles llegados a América habían introducido otros animales como caballos, vacas, toros, ovejas, entre otros; los cuales también fueron trasladados a Huánuco Pampa durante su ocupación española. Con el paso de los años estos animales domésticos traídos de Europa fueron criados por los indígenas, incorporándolos a sus creencias, y es que si bien es cierto que los camélidos desaparecieron del lugar, las necesidades de los hombres andinos fue permanente y la preocupación por la subsistencia no desapareció, es decir, fueron las condiciones extremas de escasez de pastos, enfermedades, sequías temporales, etc. las que hicieron que se aferraran a sus ideologías y creencias andinas.

Por lo tanto, en la comunidad campesina de Agüamiro el culto a la ylla relacionado al aumento y protección del ganado se ha conservado a pesar del transcurso de los siglos y de los constantes intentos de extirpar las idolatrías en las zonas alto andinas del Perú.

\section{Agradecimientos}

Van mis agradecimientos sinceros a las familias de la comunidad campesina de Agüamiro por compartir sus conocimientos más íntimos sobre el tema desarrollado. A Hernán Ramos por la revisión del texto y las sugerencias vertidas. A Tania Castro por las repetidas lecturas y sus valiosas opiniones. Y a mi familia por el aliento constante.

\section{BiBLIOGRAFÍA}

ANÓNIMO

1992 [1562] Relación de la Religión y Ritos del Perú hecha por los Padres Agustinos de Huamachuco. Editora Lucila Castro de Trelles. Lima: PUCP.

ALBORNOZ, Cristóbal de

1989 [1582] «Instrucción para Descubrir todas las Guacas del Piru y sus Camayos y Haziendas». En: H. Urbano y P. Duviols (eds.) Fábulas y Mitos de los Incas». C. de Molina, C. de Albornoz. España.

AYALA, Fabian de

1999 [1614] «Errores, ritos, supersticiones, y cere/monias de los indios dela prouincia / de chinchay cocha y otras del piru». En: M. Polia (ed.) La Cosmovisión Religiosa Andina, en los documentos inéditos del Archivo Romano de la Compañía de Jesús 1581 - 1752. Lima: PUCP.

\section{CABREDO, Rodrigo de}

1999 [1601] «Annua dela Proui.a del Peru / año del mil y seisçientos y vno». En: M. Polia (ed.) La Cosmovisión Religiosa Andina, en los documentos inéditos del Archivo Romano de la Compañía de Jesús 1581 - 1752. Lima: PUCP.

\section{CIEZA DE LEÓN, P.}

1928 [1553] La Crónica del Perú. Biblioteca de Autores Españoles. Historiadores Primitivos de Indias. Tomo Vigésimosexto. Tomo II. Madrid: Librería y Casa Editorial Hernando S.A.

CONDORI, B. y Gow, ROSALIND

1982 Kay Pacha. Biblioteca de la Tradición Oral Andina 1. Bartolomé de las Casas.

DELGADO DE THAYS, Carmen

1965 Religión y Magia en Tupe (Yauyos). Serie: Tesis Antropológicas, N². Instituto de Estudios Etnológicos del Museo Nacional de la Cultura Peruana. UNMSM. 
ESTETE, Miguel

1917 [1533] «La relación del viaje que hizo el señor capitán Hernando Pizarro por mandado del Señor Gobernador, su hermano, desde el pueblo de Caxamalca a Pachacama y de allí a Jauja». En: H. Urteaga (ed.) Las Relaciones de la Conquista del Perú, por Francisco de Jerez y Pedro Sancho, Imprenta y Librería Sanmarti.

FLORES O., Jorge A.

1977 Enqa, enqaychu, illa y Khuya rumi. En: Pastores de Puna. Uywamichiq punarunakuna. Instituto de Estudios Peruanos. $1^{\underline{a}}$ edición. Impreso en Perú.

MANRÍQUEZ, Viviana

1999 «El término Ylla y su potencial simbólico en el Tawantinsuyu. Una reflexión acerca de la presencia inca en Caspana (río Loa, desierto de Atacama)». Estudios Atacameños 18. Instituto de Investigaciones Arqueológicas y Museo. Universidad Católica del Norte. II Región - Chile.

MONTESINOS, Fernando de

1930 [1644] Memorias Antiguas Historiales y Políticas del Perú. Colección de libros y Documentos referentes a la historia del Perú. Ed. de Horacio Urteaga. Lima. Librería e Imprenta Gil.

MORRIS, Craig y Alan COVEY

2003 «La Plaza Central de Huánuco Pampa: Espacio y Transformación». Boletín de Arqueología PUCP 7. Lima.

OLIVA, R. P. Anello

1895 [1631] Historia del Reino y Provincias del Perú. Libro Primero del Manuscrito Original. Imprenta y Librería de S. Pedro.

POLIA M., Mario

1999 La Cosmovisión Religiosa Andina en los documentos inéditos del Archivo Romano de la Compañía de Jesús 1581-1752. Lima: PUCP.

TAIPE C., Néstor

1991 Ritos Ganaderos Andinos. Editorial Horizonte. Etnología y Antropología 3. Lima.

TOSI, Joseph

1960 «Zonas de Vida Natural en el Perú. Memoria Explicativa sobre el Mapa Ecológico del Perú». Boletín Técnico 5. Instituto Interamericano de Ciencias Agrícolas de la OEA Zona Andina.

YAURI M., Marcos

2007 Simbolismo de la Plantas Alimenticias en los Andes: Illas y Conopas. Mapa Cultural y Educación en el Perú. Tomo I, Selección y Notas: Wilfredo Kapsoli Escudero. Asamblea Nacional de Rectores. 